\title{
An evaluation of Molly cow model predictions of ruminal metabolism and nutrient digestion for dairy and beef diets
}

\author{
Meng M. Li, Robin R. White, and Mark D. Hanigan ${ }^{1}$ \\ Department of Dairy Science, Virginia Polytechnic Institute and State University, Blacksburg 24061
}

\begin{abstract}
Model evaluation, as a critical process of model advancement, is necessary to identify adequacy and consistency of model predictions. The objectives of this study were (1) to evaluate the accuracy of Molly cow model predictions of ruminal metabolism and nutrient digestion when simulating dairy and beef cattle diets; and (2) to identify deficiencies in representations of the biology that could be used to direct further model improvements. A total of 229 studies ( $\mathrm{n}=938$ treatments) including dairy and beef cattle data, published from 1972 through 2016, were collected from the literature. Root mean squared errors (RMSE) and concordance correlation coefficients (CCC) were calculated to assess model accuracy and precision. Ruminal $\mathrm{pH}$ was very poorly represented in the model with a RMSE of $4.6 \%$ and a CCC of 0.0. Although volatile fatty acid concentrations had negligible mean $(2.5 \%$ of mean squared error) and slope (6.8\% of mean squared error) bias, the CCC was 0.28 , implying that further modifications with respect to volatile fatty acid production and absorption are required to improve model precision. The RMSE was greater than $50 \%$ for ruminal ammonia and blood urea-N concentrations with high proportions of error as slope bias, indicating that mechanisms driving ruminal urea $\mathrm{N}$ recycling are not properly simulated in the model. Only slight mean and slope bias were exhibited for ruminal outflow of neutral detergent fiber, starch, lipid, total $\mathrm{N}$, and nonammonia $\mathrm{N}$, and for fecal output of protein, neutral detergent fiber, lipid, and starch, indicating the mechanisms encoded in the model relative to ruminal and total-tract nutrient digestion are properly represented. All variables related to ruminal metabolism and nutrient digestion were more precisely predicted for dairy cattle than for beef cattle. This difference in precision was mostly related to the model's inability to simulate low forage diets included in the beef studies. Overall, ruminal $\mathrm{pH}$ was
\end{abstract}

Received November 22, 2017.

Accepted July 12, 2018.

${ }^{1}$ Corresponding author: mhanigan@vt.edu poorly simulated and contributed to problems in ruminal nutrient degradation and volatile fatty acid production predictions. Residual analyses suggested ruminal ammonia concentrations need to be considered in the ruminal $\mathrm{pH}$ equation, and therefore the inaccuracies in predicting ruminal urea $\mathrm{N}$ recycling must also be addressed. These modifications to model structure will likely improve model performance across a wider array of dietary inputs and cattle type.

Key words: digestion, model evaluation, ruminal metabolism

\section{INTRODUCTION}

A basic goal of ruminant nutritionists is to advance animal production through a continuously improved understanding of nutrient digestion and metabolism (Baldwin, 1995). Baldwin and colleagues constructed a dynamic and mechanistic model (named Molly) by combining key biological elements of digestion and metabolism (Baldwin et al., 1987a,b,c). It is a moderately complicated system of equations describing flows of chemical entities through a series of digestive and metabolic processes. Several evaluations of digestive and metabolic elements of Molly have been undertaken, which have guided structural changes and reparameterization of the model (Hanigan, 2005; Johnson and Baldwin, 2008). Additional modifications with respect to digestive parameter estimates (Hanigan et al., 2013) and ruminal digesta outflow (Gregorini et al., 2015) have been undertaken and integrated in the Molly cow model, which have yielded increased accuracy of model predictions. Essentially all of this work has been conducted using data derived from dairy cattle, which have included very few observations with high forage (forage percentage $>70 \%$ ) and essentially no observations with very low forage feeding levels (forage percentage $<30 \%$ ) as commonly fed to beef cattle. A key aim of a mechanistic model such as Molly is, however, to capture mechanisms that allow simulations across the full range in diets and cattle categories.

It was hypothesized that the Molly model properly represents nutrient digestion and ruminal metabolism 
for high and low forage diets. The objectives of the current work were (1) to evaluate the accuracy of the Molly cow model predictions of ruminal metabolism and nutrient digestion when simulating high and low forage diets; and (2) if deficiencies are identified in the model, to identify representations of the underlying biology that could be used to direct further model improvements.

\section{MATERIALS AND METHODS}

\section{Model Description}

The current work was conducted using a modified version of Molly containing updated digestion and metabolism parameters (Hanigan et al., 2013) and an improved representation of ruminal digesta outflow (Gregorini et al., 2015). Model simulations were conducted using ACSLX (3.1.4.2, Aegis Technologies Group Inc., Huntsville, AL). The model was set to simulate $14 \mathrm{~d}$ to ensure it had reached steady state, and only predictions from the last day of the run were compared with observed values.

Model input values were either derived from literature observations or were assumed as described previously (Hanigan et al., 2013; Ghimire et al., 2014). Briefly, the model was set to use observed dietary ingredient intakes, ingredient nutrient composition, DMI, and BW as inputs, and it was assumed dietary intake was constant throughout the day. Because 32, 21, 54, 2, and $78 \%$ of studies did not report each of ADF, NDF, starch, $\mathrm{CP}$, and fat either as dietary concentrations or intakes, tabular values from NRC (2001) were used to replace the missing values. Starch solubility and degradation were predicted from Tamminga et al. (1990) or Miller-Webster and Hoover (1998), and ADF degradability was predicted from the equation of Huhtanen et al. (2010). Reference bypass values for protein were calculated from the $\mathrm{B}$ and $\mathrm{C}$ fractions of $\mathrm{CP}$ using the NRC reported $K_{d}$ and a fixed ruminal residence time for each feed as described by Hanigan et al. (2013). This allowed summation of the nonlinear elements among feeds to determine a dietary value, which was then used to back calculate to a rate of degradation by rearrangement of the initial equation. This reference rate constant was used in the model with previously derived slope and intercept adjustments to represent the base rate of degradation. Additional adjustments of the rate of degradation occur during each run based on prevailing ruminal conditions predicted by the model (e.g., the size of the microbial protein pool). The same approach was used for starch and ADF using estimated undegradability as a reference input.
To minimize mis-specification, predicted dietary nutrients were compared with reported values and any bias within study was used to adjust ingredient nutrients for that study to align observed and predicted data as described by Hanigan et al. (2013) and as follows. Bias for each nutrient $(n)$ within each study $(s)$ was derived by summation of the difference between the reported $(O b s)$ dietary nutrient intake and that predicted (Pred) from summation of tabular ingredient $(i)$ values for each diet $(d)$, and used to adjust ingredient nutrient concentrations to match reported nutrient values among treatments $(j)$ :

$$
\operatorname{Bias}_{s, n}=\sum_{d=1}^{N_{d}}\left(\operatorname{Obs}_{s, d, n}-\operatorname{Pred}_{s, d, n}\right) .
$$

Bias was converted to a proportional adjustment $\left(A d j_{s, n}\right)$ using the nutrient sum for all diets in the study:

$$
A d j_{s, n}=\frac{\text { Bias }_{s, n}}{\sum_{d=1}^{N} \operatorname{Pred}_{s, d, n}} .
$$

$A d j$ was subsequently used to adjust the nutrient content of each ingredient (Rev) among diets within each study:

$$
R e v_{s, i, n}=O b s_{s, i, n} \times\left(1+A d j_{s, n}\right) .
$$

This approach uses the diet formulas and adjusted nutrient composition of ingredients to determine nutrient differences among diets within a study and ensures that the mean nutrient content of those diets equals the observed mean values where such values have been reported. This avoids the introduction of mean input bias to the analyses and balances formulation information and reported nutrient data to better predict nutrients for each diet. Additionally, because it is applied at the ingredient level, secondary nutrients are comparably adjusted with the primary nutrient (e.g., calculated RUP will change proportional to the change in CP for each ingredient). This approach also avoids the dichotomy of effectively adjusting the nutrient content of a single ingredient to more than 1 value within a study, which would be the case if nutrients for each diet were assumed to be reported without error and used to exactly match nutrient inputs to the reported value for each diet.

Rumen fluid osmolarity is calculated by dividing the sum of the moles of soluble substrates (soluble carbohydrate, ammonia, VFA, lactate, AA, and soluble ash) 
by rumen liquid volume. Osmolarity of soluble ash was calculated by dividing soluble ash weight by the molecular weight of sodium bicarbonate and multiplying by an osmolarity factor of 1.7 (Argyle and Baldwin, 1988). Soluble ash intake is the product of DMI and the fractional content of soluble ash, where the soluble ash fraction is calculated by subtracting a fixed insoluble ash fraction of $1.2 \%$ from total dietary ash (Argyle and Baldwin, 1988).

In Molly, particle size distribution is one of the determinants of rates of particulate degradation and outflow from the rumen (Gregorini et al., 2015). Briefly, large particles are subject to size reduction through rumination and mastication; medium particles are subject to passage at a slow rate and to degradation through rumination and mastication and by microbial activity; small particles are subject to degradation by microbial activity and passage at a high rate. The particle distribution in the diet is used to determine inputs to each particle pool and the size of those pools in the rumen are predicted by integration of inputs and outputs as for other pools in the rumen. However, very few experimental studies reported dietary particle size distributions. We therefore derived 3 empirical equations to estimate accumulated percentages of particles above each of the 3 sieves in a Penn State Particle separator based on dietary forage percentages (ForP, $\%$ of diet DM). A data set of particle distributions and dietary forage content was collected from the literature (Turgeon et al., 1983; Kononoff and Heinrichs, 2003; Kononoff et al., 2003; Rustomo et al., 2006; Maulfair et al., 2011; Maulfair and Heinrichs, 2013; Ramirez Ramirez et al., 2016) and used to derive the following prediction equations:

$$
\begin{aligned}
& \text { Large } P=0.0023 \times \text { For }^{2}+0.0035 \times \text { For } P+0.2 \\
& \left(R^{2}=0.95, \mathrm{n}=8\right), \\
& \text { Medium } P=-0.008 \times \text { For }^{2}+1.48 \times \text { For } P+1.2 \\
& \left(R^{2}=0.95, \mathrm{n}=8\right), \\
& \text { SmallP }=-0.003 \times \text { For } P^{2}+0.72 \times \text { For } P+56.6 \\
& \left(R^{2}=0.58, \mathrm{n}=8\right),
\end{aligned}
$$

where LargeP (\% of DM retained) is the cumulative percentage of particles retained above the $19.05 \mathrm{~mm}$ sieve; MediumP (\% of DM retained) is the cumulative percentage of particles retained above the $7.87 \mathrm{~mm}$ sieve; and SmallP (\% of DM retained) represents the cumulative percentage of particles retained above the $1.78 \mathrm{~mm}$ sieve.

\section{Data Collection}

Data used for model evaluation were collected from 153 publications with 574 treatments conducted with dairy cattle and 76 publications with 364 treatments conducted with beef cattle. The dairy data included observations from both lactating and nonlactating animals, and consisted of the 62 experiments used by the 2001 Dairy NRC Committee (NRC, 2001), which were used for a prior evaluation and reparameterization by Hanigan et al. (2013) plus an additional 91 studies published from 2000 to 2016. A complete list of the dairy studies is included in White et al. (2017), and a copy of the data can be downloaded from the National Animal Nutrition Program website (awaiting upload). The beef data set contained observations from growing and finishing cattle. A listing of beef studies is presented in Supplemental Table S1 (https://doi.org/ 10.3168/jds.2017-14182).

Studies selected for inclusion in the data set contained DMI, diet formula information, and measurements of nutrient digestibility or ruminal metabolism. All reported data were treatment means. Body weight is a required model input. Reported initial BW was used to initialize the model for dairy cows, and the average of the initial and final BW was used for beef cattle. The average BW for dairy cattle in the data set was $595 \mathrm{~kg}$ with a $\mathrm{SD}$ of $64 \mathrm{~kg}(\mathrm{n}=522)$. Body weight was not reported for 52 treatments in the dairy data set. In these cases, initial BW was set to $600 \mathrm{~kg}$. The average BW for beef cattle in the data set was 457 $\mathrm{kg}$ with a SD of $140 \mathrm{~kg}(\mathrm{n}=322)$. Body weight was not reported for 32 treatments in the beef data set. In those cases BW was estimated from reported EBW, shrunk BW, or carcass weight based on the equations of Lofgreen et al. (1962).

Variables used to evaluate model predictions included ruminal outflow of DM, ADF, NDF, starch, lipid, total $\mathrm{N}$, microbial $\mathrm{N}$, nonammonia $\mathrm{N}$, and nonammonia, nonmicrobial N (NANMN); and fecal excretion of DM, protein, ADF, NDF, lipid, and starch. Ruminal $\mathrm{pH}$, ammonia concentrations, VFA concentrations, and blood urea- $\mathrm{N}$ concentrations were also used to evaluate ruminal fermentation parameters. A statistical summary of the observations is presented in Table 1. Observed data were assessed for variance and normality. Given the relatively discrete diet types, the input and observed data were not normally distributed for many measurements. Exceptions were starch intake, ruminal digestibility of $\mathrm{OM}$ and $\mathrm{ADF}$, total-tract digestibility 
of ADF and NDF, and blood urea concentrations. This does not imply that the population of all diets cannot be normally distributed, only that the sampling of diets within the population was not homogeneous, and likely cannot be homogeneous given the nature of diet design. This does not affect model performance, and most measures of model performance will be unaffected as the model will account for differences in diets resulting in normally distributed residual errors. Individual data points with absolute values greater than 3 standard deviations from the mean were considered outliers, and around $1 \%$ of the observations were removed from the data set.

High forage and low forage diets were identified based on the forage percentage and used to categorize the data. If the forage percentage was equal to or greater than $70 \%$, the diet was categorized as a high forage diet; if the forage percentage was equal or less than $30 \%$, the diet was categorized as a low forage diet. The remainder were categorized as moderate forage. Using these criteria, the data set contained $10 \%$ high forage diets, $33 \%$ low forage diets, and $57 \%$ moderate forage diets. Both dairy and beef data were included in the low, moderate, and high forage diets. A summary of nutrient composition for the 3 categories is described in Table 2.

\section{Model Evaluation}

Mean squared error (MSE) which is the sum of the squared residual errors divided by the number of observations was used to calculate the root MSE (RMSE) and to partition the MSE into slope and mean bias (Bibby and Toutenburg, 1977). Concordance correla-

Table 1. Observed nutrient intakes, ruminal digestibility, ruminal outflow and metabolism, and total-tract digestibility

\begin{tabular}{|c|c|c|c|c|c|}
\hline Item & $\mathrm{N}$ & Mean & $\mathrm{SD}$ & Minimum & Maximum \\
\hline $\mathrm{BW}, \mathrm{kg}$ & 886 & 548 & 117 & 240 & 807 \\
\hline \multicolumn{6}{|l|}{ Intake, $\mathrm{kg} / \mathrm{d}$} \\
\hline DM & 938 & 15.3 & 6.2 & 3.0 & 30.4 \\
\hline $\mathrm{OM}$ & 632 & 15.9 & 5.3 & 2.8 & 29.5 \\
\hline $\mathrm{ADF}$ & 353 & 3.5 & 1.4 & 0.3 & 6.7 \\
\hline $\mathrm{NDF}$ & 538 & 5.9 & 2.2 & 1.0 & 12.4 \\
\hline Starch & 346 & 5.2 & 2.0 & 0.2 & 11.0 \\
\hline \multicolumn{6}{|l|}{ Ruminal digestibility, \% } \\
\hline $\mathrm{OM}$ & 473 & 57.2 & 10.7 & 19.6 & 84.2 \\
\hline Nitrogen & 320 & 56.6 & 13.7 & 9.2 & 91.0 \\
\hline $\mathrm{ADF}$ & 273 & 40.3 & 12.8 & 6.2 & 77.5 \\
\hline NDF & 459 & 44.4 & 13.0 & 4.8 & 84.4 \\
\hline Starch & 292 & 66.0 & 18.5 & 4.5 & 94.2 \\
\hline Lipid & 39 & 9.0 & 9.9 & -17 & 26.2 \\
\hline \multicolumn{6}{|l|}{ Ruminal outflow, $\mathrm{kg} / \mathrm{d}$} \\
\hline DM & 152 & 13.7 & 4.1 & 2.2 & 24.2 \\
\hline $\mathrm{OM}$ & 430 & 10.2 & 4.1 & 1.7 & 20.6 \\
\hline $\mathrm{ADF}$ & 225 & 2.2 & 0.9 & 0.2 & 4.2 \\
\hline NDF & 342 & 3.4 & 1.3 & 0.7 & 6.5 \\
\hline Starch & 225 & 2.2 & 1.5 & 0.03 & 5.8 \\
\hline Lipid & 30 & 1.0 & 0.4 & 0.5 & 2.0 \\
\hline Total N & 510 & 0.5 & 0.2 & 0.07 & 1.0 \\
\hline Microbial N & 625 & 0.3 & 0.1 & 0.05 & 0.7 \\
\hline Nonammonia N & 566 & 0.5 & 0.2 & 0.07 & 1.1 \\
\hline Nonammonia, nonmicrobial $\mathrm{N}$ & 560 & 0.2 & 0.1 & 0.01 & 0.6 \\
\hline \multicolumn{6}{|l|}{ Rumen fermentation } \\
\hline $\mathrm{pH}$ & 611 & 6.1 & 0.3 & 5.5 & 6.8 \\
\hline Ammonia, mg/dL & 538 & 12.4 & 5.1 & 0.1 & 30.3 \\
\hline Blood urea-N, mg/dL & 114 & 12.3 & 4.2 & 1.7 & 23.4 \\
\hline Total VFA, mM & 584 & 108.8 & 21.9 & 37.1 & 161 \\
\hline Acetate, $\%$ of VFA & 629 & 60.9 & 6.6 & 36.4 & 77.3 \\
\hline Proionate, $\%$ of VFA & 629 & 23.2 & 6.0 & 12.5 & 44.0 \\
\hline Butyrate, $\%$ of VFA & 629 & 11.7 & 2.0 & 5.7 & 19.9 \\
\hline \multicolumn{6}{|l|}{ Total-tract digestibility, $\%$} \\
\hline $\mathrm{DM}$ & 396 & 68.9 & 6.5 & 48.2 & 85.7 \\
\hline $\mathrm{OM}$ & 606 & 70.9 & 6.8 & 43.8 & 87.4 \\
\hline Nitrogen & 560 & 67.88 & 5.2 & 51.5 & 82.0 \\
\hline $\mathrm{ADF}$ & 326 & 45.2 & 11.6 & 11.9 & 77.2 \\
\hline $\mathrm{NDF}$ & 546 & 51.0 & 11.5 & 13.2 & 84 \\
\hline Starch & 312 & 92.6 & 6.7 & 68.4 & 99.7 \\
\hline Lipid & 92 & 72.1 & 13.8 & 20.9 & 93.6 \\
\hline
\end{tabular}


Table 2. Nutrient composition of low, moderate, and high forage $\operatorname{diets}^{1}$

\begin{tabular}{|c|c|c|c|c|c|c|}
\hline \multirow[b]{2}{*}{ Item } & \multicolumn{2}{|c|}{ Low forage } & \multicolumn{2}{|c|}{ Moderate forage } & \multicolumn{2}{|c|}{ High forage } \\
\hline & Mean & $\mathrm{SD}$ & Mean & SD & Mean & $\mathrm{SD}$ \\
\hline $\mathrm{CP}, \%$ & 15.1 & 3.2 & 16.8 & 2.4 & 15.7 & 4.5 \\
\hline Fat, $\%$ & 4.7 & 1.8 & 3.9 & 1.7 & 2.7 & 0.7 \\
\hline Starch, \% & 47.5 & 11.3 & 30.6 & 7.7 & 19.7 & 9.9 \\
\hline NDF, $\%$ & 21.2 & 8.6 & 33.4 & 6.4 & 50.9 & 13.5 \\
\hline $\mathrm{ADF}, \%$ & 10.6 & 5.2 & 20.1 & 4.6 & 32.7 & 10.3 \\
\hline Lignin, \% & 2.4 & 1.2 & 3.5 & 1.0 & 4.9 & 1.6 \\
\hline
\end{tabular}

${ }^{1}$ Both dairy and beef data were included in the low, moderate, and high forage diets.

tion coefficients (CCC) were also calculated from the residuals. This value represents the correlation between observed and predicted variables (Lin, 1989).

Multivariate regression of residuals for predictions of ruminal nutrient outflow and ruminal metabolites on animal, dietary, and ruminal fermentation parameters were conducted to identify model elements for improvement. The presence of a significant relationship suggests the model might not properly represent the effects or fate of that nutrient. These residual analyses were conducted by regressing residuals on observed BW, DMI, dietary nutrient composition (ADF, rumen undegraded ADF, NDF, forage NDF, starch, soluble starch, rumen undegraded starch, CP, soluble CP, RUP, NPN, urea, lipid, lignin, ash, roughage), predicted ruminal $\mathrm{pH}$, and predicted ammonia concentrations. When ex- amining residual errors of prediction for ruminal $\mathrm{pH}$ or ammonia, that variable was not included as an independent variable in the regression model. Study effect was included as a random variable and regressions were conducted using a backward elimination approach with a significance level of 0.1 . Multicollinearity was assessed by calculation of variance inflation factors with variables having variance inflation factors greater than 10 removed from the regression model (Craney and Surles, 2002). In these analyses, positive coefficients indicate the model underpredicted responses to the independent variable, whereas negative coefficients imply overprediction of responses. As illustrated in Figure 1, a negative correlation is present between ruminal $\mathrm{pH}$ and residuals of ruminal ADF outflow. Residuals of ruminal ADF outflow decrease with increased predicted ruminal
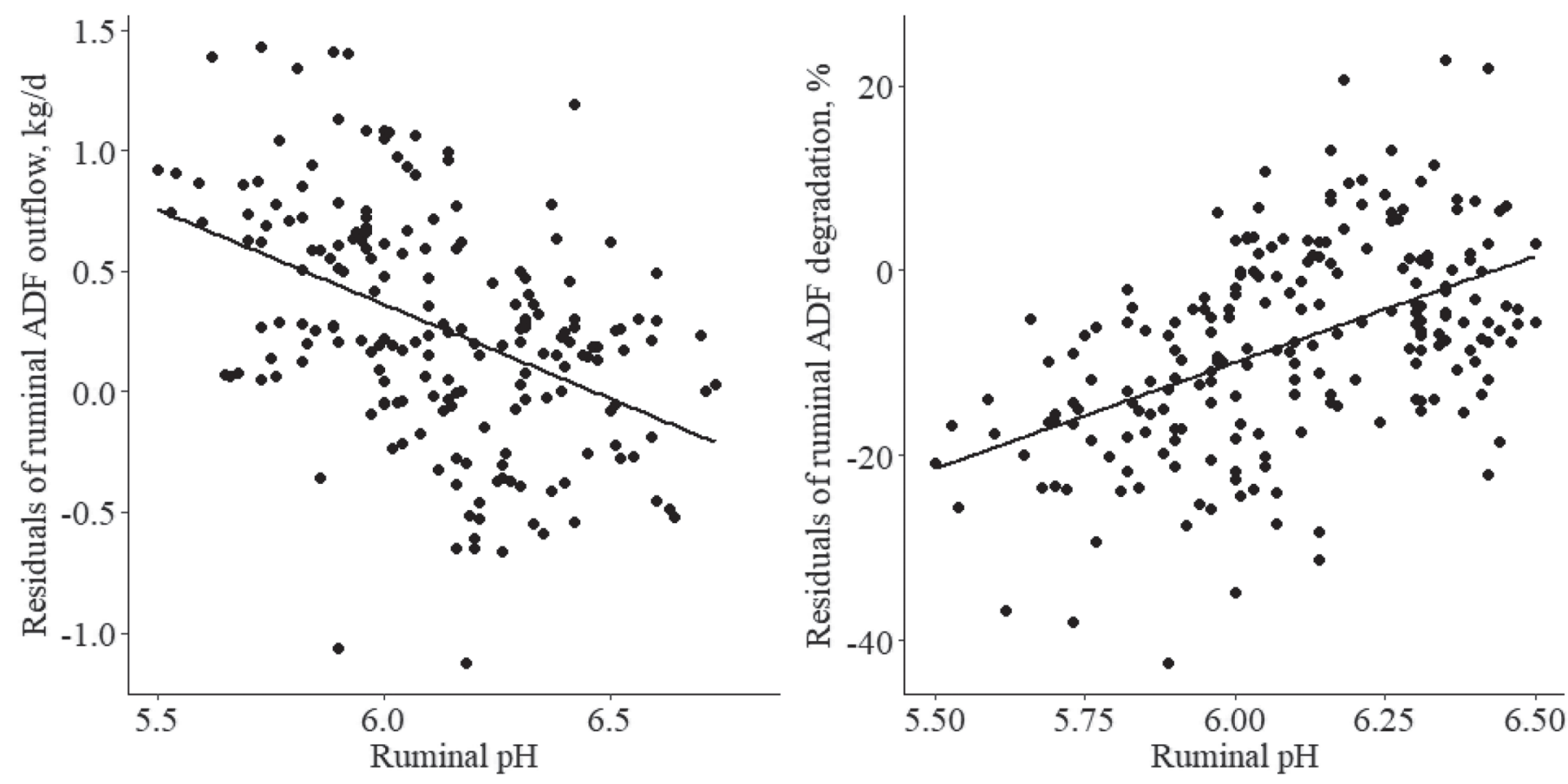

Figure 1. Residuals for ruminal ADF outflow (kg/d) or degradation (\%) versus ruminal $\mathrm{pH}$. Residuals are calculated as observed minus predicted values. 
$\mathrm{pH}$ being slightly underpredicted at low $\mathrm{pH}$ and becoming overpredicted at high $\mathrm{pH}$.

Simple linear regression analyses of residuals for fecal nutrient excretions (DM, protein, ADF, NDF, starch, and lipid) were conducted by regressing residuals on predicted ruminal outflow of a nutrient. Significant regression coefficients indicate digestion coefficients were improperly specified. Positive coefficients indicate fecal nutrient outputs were underpredicted with increased ruminal nutrient outflow, whereas negative coefficients imply fecal nutrient outputs were overpredicted. Data handling and residual analyses were conducted using $\mathrm{R}$ software (ver. 3.3.0).

\section{RESULTS AND DISCUSSION}

\section{Bias Adjustment for Nutrient Compositions}

A summary of bias adjustments for dietary nutrients is shown in Table 3. Without bias adjustments, RMSE (\% of mean) for dietary CP, NDF and ADF concentrations was 11.2, 13.8, and 18.5\%, respectively. Bias corrections reduced the RMSE for $\mathrm{CP}, \mathrm{NDF}$, and ADF to $8.9,10.8$, and $14.1 \%$, respectively. The decreased RMSE were primarily due to decreased mean and slope bias.

\section{Nutrient Outflow from the Rumen}

The initial evaluation of RMSE for nutrient digestion and ruminal metabolism was conducted across diet types (Table 4). Root mean squared errors of ruminal outflow of DM, ADF, NDF, lipid, and total $\mathrm{N}$ were $17.9,25.8,26.3,14.1$, and $19.4 \%$, respectively, and CCC were $0.8,0.8,0.7,0.9$, and 0.8 , indicating that the model simulated ruminal outflow of these nutrients with reasonable accuracy and precision. Gregorini et al. (2015) developed an improved representation of ruminal digesta outflow in the model. Although the modifications did not substantially improve the accuracy of digestive functions in their analyses, the model did reproduce more realistic trends in rumen particle outflow, fermentation patterns, digestion, and methane yields. Previous studies assumed all diets had the same particle size distribution, with no consideration of particle size on ruminal outflow and residence time. In the current work, we used an empirical equation to predict particle distribution based on dietary forage percentages. It would have been better to use observed data, but in the absence of such information, LargeP, MediumP, and SmallP were predicted with a RMSE of $19.2,9.5$, and $11.8 \%$, and a CCC of $0.98,0.98$, and 0.74 , respectively (Figure 2), suggesting that forage content captures much of the variation in particle size distribution. Because particle size, in practice, varies with degree of mixing or length of time that the ration spends in a mixer wagon, those equations may not be an appropriate representation of all diets and thus may have contributed to performance issues for the disparate beef diets. However, in most cases, the direction of change in the particle size of the diets should have been correct as forage will always have longer mean particle size than concentrates provided the forage is not ground or highly processed.

Ruminal ADF and NDF Outflow. Both ruminal ADF and NDF outflow were underpredicted with an average mean bias of 19 and $0.1 \%$ slope bias (Table 4 ), indicating that degradation rates of cellulose and hemicellulose were overspecified. Residual errors for ruminal ADF outflow were positively correlated with dietary concentrations of rumen undegraded starch, ash, and NPN (excluding urea); and negatively correlated with BW, dietary concentrations of forage NDF, urea, ruminal $\mathrm{pH}$, and ruminal ammonia concentrations (Table 5). A positive correlation was observed between residual errors for NDF outflow and dietary concentrations of ADF, forage NDF, rumen undegraded starch, and lipid; and a negative correlation with BW, dietary concentrations of $\mathrm{NDF}, \mathrm{CP}$, ruminal $\mathrm{pH}$, and ruminal ammonia concentrations. The correlations with ADF, $\mathrm{NDF}$, starch, forage, and $\mathrm{pH}$ are likely all related to the common mechanism of ruminal $\mathrm{pH}$. Indeed, residual errors for both ADF and NDF outflow were negatively

Table 3. Consequence of dietary nutrient bias adjustments on predicted dietary nutrient composition

\begin{tabular}{|c|c|c|c|c|c|c|}
\hline \multirow[b]{2}{*}{ Item } & \multicolumn{2}{|c|}{$\mathrm{CP}, \%$} & \multicolumn{2}{|c|}{ NDF, $\%$} & \multicolumn{2}{|c|}{$\mathrm{ADF}, \%$} \\
\hline & Initial & Final & Initial & Final & Initial & Final \\
\hline Observed mean & 17.1 & 17.1 & 32.9 & 32.9 & 19.5 & 19.5 \\
\hline Predicted mean & 17.2 & 17.2 & 32.0 & 32.3 & 20.3 & 20.1 \\
\hline RMSE, ${ }^{1} \%$ mean & 11.2 & 8.9 & 13.8 & 10.8 & 18.5 & 14.1 \\
\hline Mean bias, $\% \mathrm{MSE}^{2}$ & 0.3 & 0.6 & 4.0 & 3.3 & 5.6 & 4.6 \\
\hline Slope bias, \% MSE & 32.8 & 21.3 & 13.0 & 5.8 & 12.3 & 3.8 \\
\hline Residual error, \% MSE & 66.9 & 78.2 & 83.1 & 90.9 & 82.1 & 91.6 \\
\hline
\end{tabular}


Table 4. Model evaluations using a combination of dairy and beef data

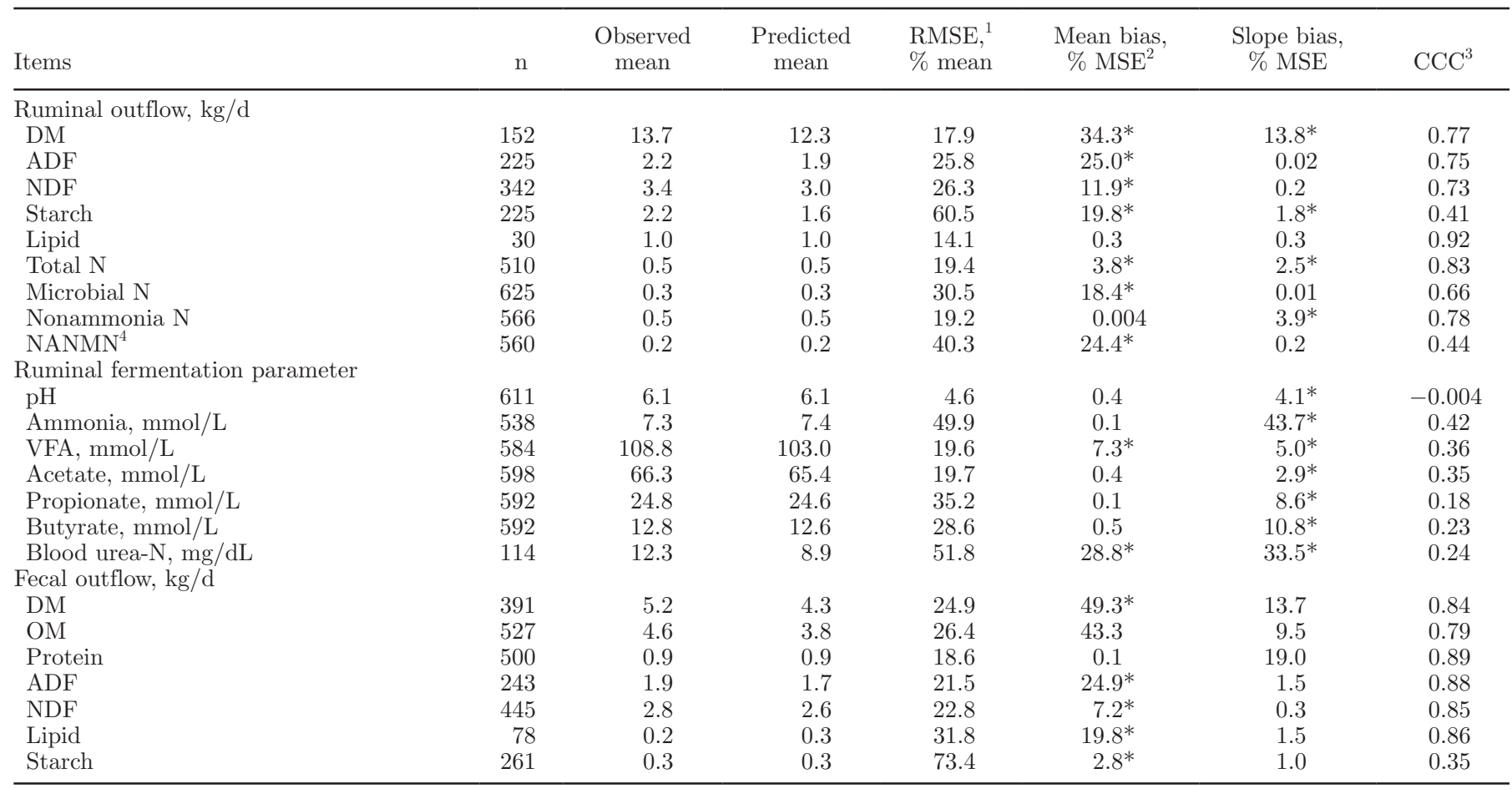

${ }^{1} \mathrm{RMSE}=$ root mean squared error.

${ }^{2} \mathrm{MSE}=$ mean squared error.

${ }^{3} \mathrm{CCC}=$ concordance correlation coefficient.

${ }^{4} \mathrm{NANMN}=$ nonammonia, nonmicrobial $\mathrm{N}$.

* denotes model bias is significantly different from $0(P<0.05)$.

correlated with predicted ruminal $\mathrm{pH}$, indicating that as $\mathrm{pH}$ increases, residuals for outflow become less (i.e., the change in outflow with respect to the change in $\mathrm{pH}$ is too great). This indicates the inhibition of fiber degradation by low $\mathrm{pH}$ encoded in the model is too responsive, causing too-large changes in fiber degradation across the range in $\mathrm{pH}$ (Figure 1). The model uses a constant of $0.1875 \mathrm{~kg} / \mathrm{kg}$ reduction in degradation per 0.1 unit drop in ruminal pH below 6.2 (Baldwin, 1995). Based on the residuals, it would appear there is no break point at 6.2 , and the inhibition slope should be less. From $\mathrm{pH} 5.5$ to 6.0 , the change in residual error for predicted digestibility is approximately $10 \%$ units. Dividing by 5 increments of $0.1 \mathrm{pH}$ change yields a slope bias of 0.2 , which is almost the same as the inhibition constant, suggesting that inhibition is near 0 within this $\mathrm{pH}$ range. Assuming predictions of $\mathrm{pH}$ are related to reality, which is open for question, further work is required to address this mechanism in the model.

The negative correlations of residual errors for predictions of ruminal ADF and NDF outflow with dietary $\mathrm{CP}$ and ruminal ammonia indicate changes in degradation rates were overly responsive to those driving variables. Considering that predicted ammonia concentrations have a substantial RMSE (Table 4), which might have created an artificial relationship, residuals of ruminal ADF and NDF outflow were also regressed on observed concentrations, and found to also be negatively correlated with observed concentrations $(P<0.05)$. This indicated that the initial regression was not entirely driven by model bias. However, the model does not contain a direct link between fiber degradation rates and nitrogen inputs or factors. Those rates are only a function of fiber pool size, $\mathrm{pH}$, and microbial mass. Therefore the over-responsiveness must be driven through inappropriate changes in microbial activity due to one of those factors within the model. The lack of a correlation between microbial flow and ruminal ammonia suggests the problem lies with $\mathrm{pH}$.

Predictions of microbial growth in the model are driven primarily by energy supply with the yield per unit of ATP affected by ruminal ammonia concentrations and AA and peptide concentrations in a saturationdependent manner with a half maximal response at 0.2 $\mathrm{m} M$ for ammonia and $0.1 \mathrm{~m} M$ for AA and peptides (Baldwin, 1995; Hanigan et al., 2009, 2013). Thus, under almost all normal feeding conditions, the modeled ammonia response is saturated. If true, the fiber 
problem seems more likely to be the related to inappropriate microbial responsiveness to $\mathrm{CP}$ and soluble $\mathrm{CP}$, although the data are not entirely consistent. The microbial responses will be discussed further below.

Ruminal Starch Outflow. Ruminal starch outflow was predicted with a RMSE of $60.5 \%$ (19.8\% mean bias and $1.8 \%$ slope bias) and CCC of 0.4. High errors in observed ruminal starch outflow with a mean of 2.21 $\mathrm{kg} / \mathrm{d}$ and a standard deviation of $1.48 \mathrm{~kg} / \mathrm{d}$ (Table 1) contribute to the substantial RMSE. A portion of this error is likely due to varied sample collection and measurement methods. There was a negative correlation between residual errors for starch outflow and BW, dietary concentrations of rumen undegraded ADF, lignin and ruminal $\mathrm{pH}$, and a positive correlation with $\mathrm{DMI}$,
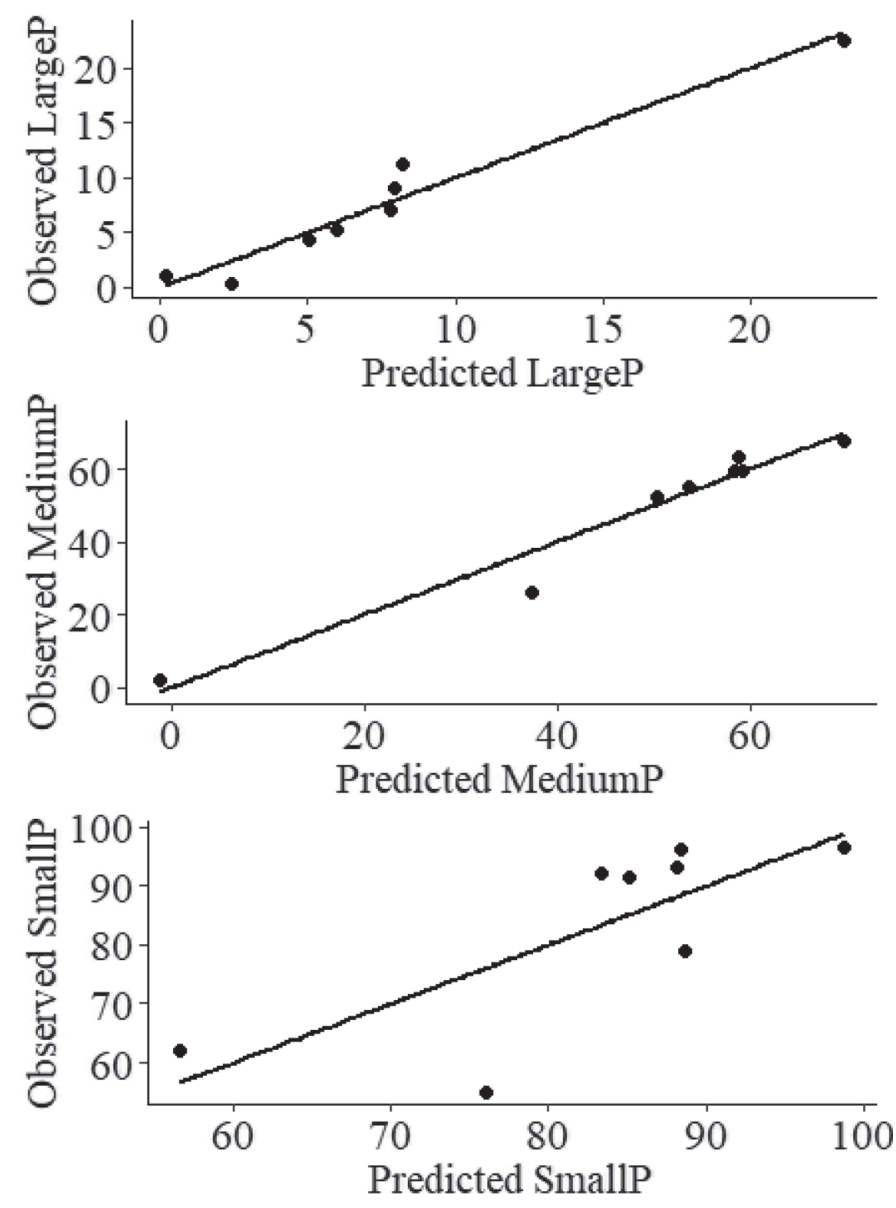

Figure 2. Observed versus predicted accumulated percentages of particles. LargeP (\% of DM retained) is the cumulative percentage of particles retained above the 19.05-mm sieve; MediumP (\% of DM retained) is the cumulative percentage of particles retained above the 7.87-mm sieve; and SmallP (\% of DM retained) represents the cumulative percentage of particles retained above the 1.78-mm sieve. LargeP, MediumP, and SmallP were predicted with a root mean squared error of $19.2,9.5$, and $11.8 \%$, and a concordance correlation coefficient of $0.98,0.98$, and 0.74 , respectively. dietary concentrations of NDF, forage NDF, soluble starch, and dietary CP (Table 5). These correlations implied that ruminal starch degradability varied depending on forage source, starch fermentability, and CP level. Variations in grain type and the processing method likely contributed to much of the variance in starch degradability because these sources of variation could not be completely represented in the model inputs due to limited reporting of ingredient characteristics. The positive correlation between residuals of ruminal starch outflow and DMI, dietary concentrations of NDF and forage NDF indicates that increasing dietary concentrations of NDF and forage NDF resulted in too-large changes in starch degradation rates. Forages affect feeding behavior and rumen particle dynamics generally resulting in reduced particle passage rates. However, the proportion of amylolytic microbes also decreases with decreased fiber content (Thoetkiattikul et al., 2013), contributing to decreased starch degradation capacity. The Molly model simulates pools of amylolytic and cellulolytic microbes from a common microbial pool based on the relative proportions of amylose and cellulose in the diet. The overall rate of microbial growth is driven by the rate of soluble sugar formation from each of the substrate pools (Baldwin, 1995), which is affected by the particulate surface area (Gregorini et al., 2015). Passage of each pool of microbes is determined by the proportion of each microbial pool attached to particles, and the liquid and particulate passage rates (Gregorini et al., 2015). Because the amylolytic microbes are not directly affected by fiber supply, any correlation in residuals would reflect the correlations among dietary NDF and dietary starch and the potential effect of dietary fiber on starch passage rates. As substrate degradation is partially driven by the microbes, there is an inherent feed forward loop within the system, but growth is ultimately limited by the overall supply of substrate. The residual errors suggest that the shift in predicted amylolytic pool size in response to changing NDF intake is too large, resulting in overly large changes in starch degradation rates. This could possibly be related to under-responsiveness in ruminal passage to ruminal load (discussed below). More dietary forage generally results in greater ruminal load. If this causes increased rates of passage and reduced residence time, changes not currently represented in the model, this could explain the interaction among dietary fiber and starch degradation.

The negative correlation between residuals of ruminal starch outflow and dietary lignin indicates ruminal starch outflow is overpredicted and starch degradation rate is underpredicted when high lignin diets are simulated. Lignin is crosslinked to polysaccharides and protein in plant cells and is largely undegradable in 
Table 5. Multivariate regression analyses of residual errors for predicted ruminal outflow ${ }^{1}$

\begin{tabular}{|c|c|c|c|c|c|c|c|c|}
\hline Independent variable & \multicolumn{8}{|c|}{ Predicted ruminal outflow } \\
\hline $\mathrm{BW}, \mathrm{kg}$ & $0.005(1.4)^{3}$ & $-0.001(1.1)$ & $-0.001(1.2)$ & $-0.002(1.6)$ & & $-0.21(1.7)$ & $-0.25(1.3)$ & \\
\hline DMI, kg & $0.16(1.9)$ & & & $0.09(2.2)$ & & $3.78(2.0)$ & $7.68(1.6)$ & \\
\hline Rumen undegraded ADF & & & & $-0.11(5.0)$ & & & & $-2.40(1.2)$ \\
\hline NDF & & & $-0.03(5.1)$ & $0.11(3.1)$ & & & $-6.46(2.9)$ & \\
\hline Forage NDF & & $-0.005(1.2)$ & $0.01(1.1)$ & $0.01(1.7)$ & $0.96(1.5)$ & & $-1.40(4.1)$ & $-0.46(1.3)$ \\
\hline \multicolumn{9}{|l|}{ Starch } \\
\hline Soluble starch & & & & $0.05(2.1)$ & $6.64(1.5)$ & & & \\
\hline Rumen undegraded starch & $-0.21(1.6)$ & $0.04(1.2)$ & $0.06(2.1)$ & & & & & \\
\hline $\mathrm{CP}$ & & & $-0.07(2.2)$ & $0.08(2.0)$ & & $4.77(3.3)$ & & \\
\hline Lignin & & & & $-0.42(2.5)$ & $10.54(1.4)$ & $9.38(1.7)$ & $10.77(2.2)$ & \\
\hline Ash & & $0.04(1.1)$ & & & & $-6.69(1.4)$ & $-13.03(1.3)$ & \\
\hline Roughage & $0.03(1.7)$ & & & & & $1.18(2.5)$ & $2.20(5.0)$ & \\
\hline \multicolumn{9}{|c|}{ Ruminal fermentation parameter } \\
\hline Ruminal $\mathrm{pH}$ & & $-1.0(1.1)$ & $-1.1(1.2)$ & $-0.69(1.4)$ & $-60.39(1.2)$ & $30.0(1.6)$ & $-36.2(1.4)$ & $-38.6(1.3)$ \\
\hline $\begin{array}{l}\text { Ruminal ammonia, } \\
\mathrm{mmol} / \mathrm{L}\end{array}$ & & $-0.06(1.2)$ & $-0.04(1.8)$ & & $-3.26(1.2)$ & & $-6.11(1.3)$ & $-5.63(1.2)$ \\
\hline $\mathrm{R}^{2}$ & 0.49 & 0.44 & 0.33 & 0.41 & 0.13 & 0.13 & 0.31 & 0.13 \\
\hline $\mathrm{RMSE}^{4}$ & 1.5 & 0.38 & 0.69 & 0.96 & 83.85 & 68.82 & 79.68 & 64.85 \\
\hline$P$-value & $<0.0001$ & $<0.0001$ & $<0.0001$ & $<0.0001$ & $<0.0001$ & $<0.0001$ & $<0.0001$ & $<0.0001$ \\
\hline
\end{tabular}

${ }^{1}$ Study effect was included as a random variable.

${ }^{2} \mathrm{NANMN}=$ nonammonia, nonmicrobial $\mathrm{N}$.

${ }^{3}$ Independent variables listed were significant $(P<0.1)$. Variance inflation factors are shown in parentheses.

${ }^{4} \mathrm{RMSE}=$ root mean squared error.

the rumen (Van Soest et al., 1991), which is resistant to digestive enzymes, leading to underestimated starch degradation rate. Our result is consistent with finding reported by White et al. (2017), suggesting that the inhibitory effect of lignin on nutrient degradation needs to be considered in the model.

Ruminal Total N, NAN, and NANMN Outflow. Ruminal outflow of total $\mathrm{N}$ and nonammonia $\mathrm{N}$ had a RMSE of $19 \%$ with an average of $2.5 \%$ mean and slope bias and a CCC of 0.8, suggesting that both total $\mathrm{N}$ and NAN outflow from the rumen were accurately and relatively precisely predicted by the model. However, NANMN outflow was underpredicted with a RMSE of $40.3 \%$ (24.4\% mean bias and $0.2 \%$ slope bias) and a CCC of 0.4 . The moderate mean bias indicates that ruminal protein degradation was overestimated, which could be addressed by a reduction in the scalar used to reference in situ determined RUP to the model rate constant for protein degradation. Nonammonia, nonmicrobial $\mathrm{N}$ residuals were negatively correlated with dietary concentrations of rumen undegraded $\mathrm{ADF}$, forage $\mathrm{NDF}$, urea, and lipid; and ruminal $\mathrm{pH}$ and ammonia concentrations (Table 5), and positively correlated with dietary NPN concentrations (excluding urea). The negative correlation between residual errors of ruminal NANMN outflow and dietary concentrations of rumen undegraded ADF indicates that with increased ruminally degraded ADF, ruminal NANMN outflow was increasingly overpredicted. Kohn and Allen (1995) reported that plant proteins are trapped in a fiber matrix, implying that increased fiber content might contribute to decreased protein degradability. The model considers ruminal protein degradation as a mass action function of the insoluble protein pool size and the microbial pool size with the rate constant set by the in situ predicted RUP as described above. As fiber degrades more slowly, on average, than protein, assuming that all of the protein degrades at a constant rate may contribute to the overprediction when more of the protein is tied up in fiber. The differential rates should be captured by the in situ data, yet the relationship exists. It is also possible the relationship is driven by the effects on increasing ruminal fiber load on ruminal passage rates. If protein turnover is reduced as more fiber 
is provided in the diet, the extent of degradation in the rumen would increase. Such an effect is represented in the model, however, the change in turnover associated with increasing fiber may not be fully captured.

The negative relationship between dietary NDF and residuals for predictions of ruminal NANMN outflow seems to contradict the negative relationship with ruminal $\mathrm{pH}$, as $\mathrm{pH}$ is generally increasing as fiber increases. Thus they may be different mechanisms. The latter suggests that protein degradation may be inhibited as ruminal pH declines. Endres and Stern (1993) observed a reduction in protein degradation when $\mathrm{pH}$ decreased from 6.3 to 5.9. Bach et al. (2005) demonstrated that ruminal $\mathrm{pH}$ can influence protein degradation by changing either predominant microbial species or enzyme activities, and ruminal proteolytic activity decreased as $\mathrm{pH}$ decreased. Therefore, it can be hypothesized that a reduction in proteolytic activity as a consequence of low $\mathrm{pH}$ would lead to proportionally greater ruminal NANMN outflow. As the model does not contain such a mechanism, the observed error patterns suggest that such an effect should be added to the model

Residuals of ruminal NANMN outflow were negatively correlated with dietary lipid, suggesting that as dietary lipid increased, feed protein degradation was underpredicted. Baldwin (1995) included a representation of the inhibitory effect of fat on fiber and protein degradation in the model. Those effects were found to be overstated and modified to reflect lesser influence by Hanigan et al. (2013). The negative correlation herein using more data suggests the prior work was not correct or necessary. It is possible that the changes in representing particle passage undertaken by Gregorini et al. (2015) may have altered the apparent responses to fat, or the addition of test data herein included a wider range of dietary fat content, which has more clearly demonstrated the mechanism. In either case, a more thorough examination of the problem is warranted.

Residual errors for ruminal NANMN outflow were also negatively correlated with dietary urea concentrations, and positively correlated with dietary NPN concentrations. Plant nucleic acids are contained within the NPN fraction as defined by the model, which account for 30 to $70 \%$ of NPN (Holt and Sosulski, 1981) and have a low solubility. This material has low susceptibility to microbial proteases and, thus, low degradability (Cecava et al., 1991). Yet it is assumed to be quantitatively converted to soluble AA and ammonia in the model, which might explain the underpredicted responses in NANMN outflow as dietary NPN input increases. It is more difficult to envision a mechanism that would explain the urea results. The results suggest that urea somehow stimulates protein degradation in the rumen.
Given that proteases derive from the microbes, it is possible that it has a stimulatory effect on microbial growth rates above the $\mathrm{N}$ concentrations normally considered to be sufficient. This may be more likely to occur on several the high-grain, feedlot diets (Huntington and Archibeque, 2000; Griswold et al., 2003). However, there is no evidence for bias in predictions of microbial flow with respect to dietary urea, and thus little support for such a hypothesis.

Microbial N Outflow. Microbial N outflow was predicted with an RMSE of $30.5 \%$, which partitioned as $18.4 \%$ mean bias and $0.01 \%$ slope bias. Compared with total $\mathrm{N}$ and nonammonia $\mathrm{N}$ outflow, which had RMSE of less than 19\%, it seems microbial growth is not well represented. Residual errors of microbial N outflow were positively correlated with DMI, dietary concentrations of $\mathrm{CP}$, lignin, roughage, and ruminal $\mathrm{pH}$, and negatively correlated with $\mathrm{BW}$, dietary concentrations of ADF, soluble CP, RUP, and ash (Table 5 ). The positive correlation between microbial $\mathrm{N}$ outflow residuals and dietary lignin indicates microbial $\mathrm{N}$ outflow is underpredicted when high lignin diets are fed, which is consistent with the inhibitory effect of lignin on nutrient degradation as discussed above. The negative correlation with soluble $\mathrm{CP}$ suggests that increasing dietary soluble N (ammonia, AA, and peptide) results in too-large changes in predicted ruminal microbial N outflow. Russell et al. (1992) found that nonstructural carbohydrate-degrading bacteria are the primary users of AA and peptides, and structural carbohydrate-degrading bacteria prefer to use ammonia. As noted above, microbial growth predictions in the model are driven by ruminally available ATP, AA, and peptide concentrations, and ammonia concentrations (Baldwin, 1995). The current results suggest that the stimulatory effect of soluble $\mathrm{N}$ is too large, leading to erroneous predictions of microbial growth. However, the negative correlation with RUP does not support such a point unless it is capturing some components of urea recycling to the rumen. If the over-responsiveness of microbial growth to soluble $\mathrm{N}$ is valid, it suggests the over-responsiveness of fiber degradation noted above may be at least partially due to challenges in the representation of $\mathrm{N}$ effects on microbial growth. However, predictions of ammonia and $\mathrm{pH}$ predictions must be corrected, and the model retested to verify that relationship. The positive relationship of residuals with DMI, roughage, and ruminal $\mathrm{pH}$ may all be reflective of too small of passage rate changes as intake and forage load increases, and passage plus high substrate supply associated with low $\mathrm{pH}$ conditions. Because the regressions only examined linear effects, any quadratic relationships would be reflected through a combination 
of multiple linear elements. A quadratic response in the residuals for microbial $\mathrm{N}$ outflow relative to dietary concentrations of $\mathrm{CP}$, soluble protein and RUP was examined based on the fitted linear regression model. Both dietary $\mathrm{CP}$ and soluble protein had a quadratic relationship with microbial $\mathrm{N}$ outflow residuals $(P=$ 0.08 and 0.01 ), which might explain why all 3 variables were in the model with seemingly opposing slopes.

$B W$ Effect on Ruminal Nutrient Outflow. The negative correlations of residual errors for predictions of ruminal ADF, NDF, starch, NAN, and microbial N outflow from the rumen with BW indicate that flows are overpredicted at high BW and the reverse at low BW. The particle passage model (Gregorini et al., 2015) is driven solely by the proportion of insoluble matter in liquid and the liquid outflow rate with no regulation. Liquid volume is a function of ruminal osmolarity as determined from the solute load in the rumen. This representation has no maximal value, but given that solute load is a function of DMI which is a biological input, there is in essence an upper limit to the volume. However, this upper limit is solely a function of DMI and dietary characteristics dictating the soluble matter. Obviously, the rumen cannot hold an unlimited volume of material. The negative relationship of residual errors for all of these entities with BW seems to suggest that rumen volume may be increasing disproportionately at high BW, leading to increased residence time and extent of digestion (i.e., the rate constant for passage increases as ruminal volume gets large relative to a given animal size). As the larger animals were all dairy animals, it seems quite likely they would have larger rumen volumes on average than the beef animals given the selection pressure for milk yield and DMI, and they may have higher passage rate constants to mitigate the large increases in DMI. Regulation of particle and fluid passage was not considered by Gregorini et al. (2015) due to the very limited quantity of data available for characterization of the particle passage equations, and this pattern of errors was not previously observed, perhaps due to the restriction of evaluations to data derived solely from dairy animals. This problem could be addressed through the addition of the concept of a maximal rumen volume driven by BW and perhaps breed. Passage rate could be modified to include the relative rumen fill as an affecter of the rate of passage.

\section{Ruminal Metabolism}

Ruminal $\boldsymbol{p H}$. Ruminal $\mathrm{pH}$ was predicted with a RMSE of $4.6 \%$ with $0.4 \%$ mean and $4.1 \%$ slope bias (Figure 3), which was consistent with the previous report after reparameterization of a modified $\mathrm{pH}$ predic- tion equation (Hanigan et al., 2013; Gregorini et al., 2015). However, the CCC was -0.004 (Figure 3), indicating that the model explains none of the variance in observed ruminal $\mathrm{pH}$. The predicted ruminal $\mathrm{pH}$ ranged from 5.99 to 6.32 , whereas the observed ranged from 5.50 to 6.81 , which is 4 times greater than predicted. Residual analyses indicated that errors were negatively correlated with dietary concentrations of soluble starch and ash and ruminal ammonia concentrations, and positively correlated with dietary ADF and NPN (Table 6 ), implying that the empirical representation of $\mathrm{pH}$ in the rumen is not fully representative. According to the Henderson-Hasselbalch equation, ruminal $\mathrm{pH}$ should be affected by acid-base relevant factors including $\mathrm{H}^{+}$ production rates; VFA, lactic acid, bicarbonate, and $\mathrm{NH}_{3}$ concentrations; partial pressure of $\mathrm{CO}_{2}$; and the buffering capacity of feed and microbial matter (Dijkstra et al., 2012). The model predicts ruminal $\mathrm{pH}$ using only total ruminal VFA and lactate concentrations as described by Argyle and Baldwin (1988). Those equations were subsequently re-parameterized by fitting to a dairy data set by Hanigan et al. (2013), which improved the RMSE. However, the negative correlation between $\mathrm{pH}$ residuals and dietary soluble starch implies that the effect of VFA production may be overpredicted when high soluble starch diets are fed.

The positive correlation between $\mathrm{pH}$ residuals and dietary ADF suggests ruminal $\mathrm{pH}$ was underpredicted with high forage diets, indicating that $\mathrm{pH}$ was affected by fiber buffering capacity which is not reflected in the model. Bicarbonate is the most important ruminal buffer, which can enter the rumen through saliva secretion or in the bicarbonate dependent absorption of VFA (Dijkstra et al., 2012). Long forage particles in the diet can affect digesta stratification and promote ruminating and salivary secretion, which helps neutralize the accumulated acids in the rumen (Yang et al., 2001). Considering fiber buffering effects may improve representations of ruminal acid-base balance, leading to accurate predictions of ruminal $\mathrm{pH}$.

Ammonia has a high $\mathrm{p} K_{\mathrm{a}}(9.21)$, and thus is primarily present in the rumen as $\mathrm{NH}_{4}{ }^{+}$(Dijkstra et al., 2012). Abdoun et al. (2007) indicated that at $\mathrm{pH}$ of 6.5 or lower, $\mathrm{NH}_{3}$ is predominantly absorbed as $\mathrm{NH}_{4}^{+}$by a putative $\mathrm{K}$ channel, which can neutralize acidity through the disposal of $\mathrm{NH}_{4}{ }^{+}$. Argyle and Baldwin (1988) adapted the ruminal $\mathrm{pH}$ equation from Briggs et al. (1957) where the original equation used total ruminal VFA, lactate, and ammonia concentrations as driving variables. The residuals regression analyses suggested that ammonia concentrations need to be reinstated as a variable to reflect $\mathrm{H}^{+}$removal during absorption, and such a change could yield a better representation of ru- 

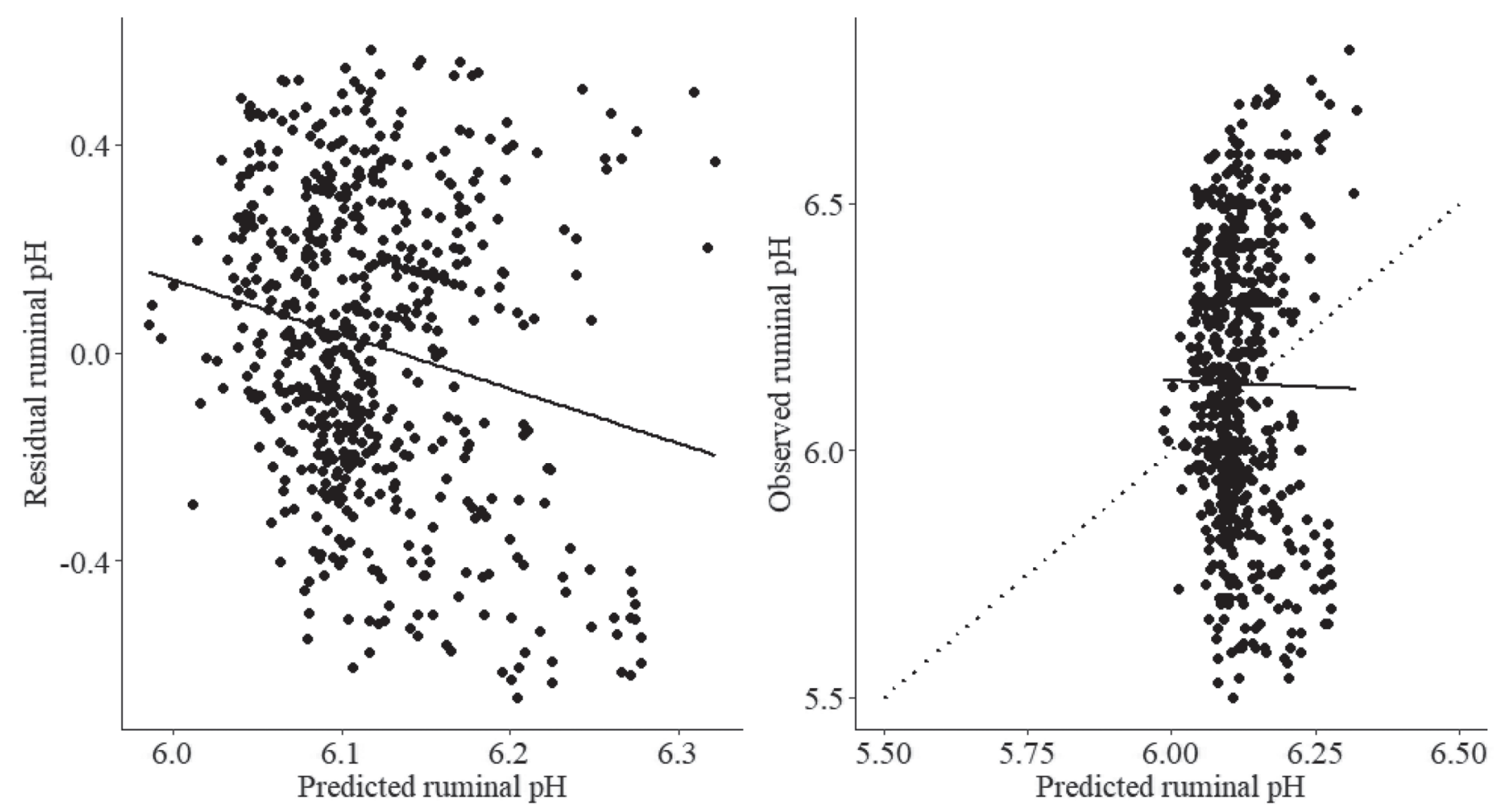

Figure 3. Observed or residual ruminal $\mathrm{pH}$ for predictions of ruminal $\mathrm{pH}$ (concordance correlation coefficient $=-0.004$, root mean squared error $=4.6 \%$, mean bias $=0.4 \%$ MSE, slope bias $=4.1 \%$ MSE, $\mathrm{n}=611$ ). MSE represents mean squared error; the solid line represents the regression line, and the dotted line represents the line of unity.

minal $\mathrm{pH}$ predictions. However, predictions of ruminal ammonia and VFA should be unbiased if such a scheme is to be introduced.

Ruminal VFA Concentrations. Root mean squared errors for total VFA, acetate, propionate, and butyrate concentrations were 19.6, 19.7, 35.2, and $28.6 \%$, respectively, with an average of $2.1 \%$ of MSE as mean bias and $6.8 \%$ as slope bias. Although low proportions of error as mean and slope bias were observed, CCC ranged from 0.18 to 0.36 , indicating a large amount of unexplained variation. All of the VFA concentrations were underpredicted even though ruminal degradation of ADF, NDF, and starch were overestimated. The discrepancy in mean biases in VFA and ruminal nutrient degradation predictions suggests that either rates of production or absorption are improperly represented in the model. Although a portion of the residual variation is likely due to sampling variability (Lane et al., 1968), regression analyses indicated that residual errors for each of the VFA concentrations were negatively correlated with ruminal $\mathrm{pH}$ (Table 6). The model predicts individual VFA from fermentable soluble carbohydrate, hemicellulose and cellulose, dietary AA, and lactic acid from silage as originally described by Murphy et al. (1982). Production rates of each are influenced by ruminal $\mathrm{pH}$ where the yield of propionate is increased, and the yields of acetate and butyrate are reduced with low pH (Argyle and Baldwin, 1988). Thus, the lack of precision in predicting $\mathrm{pH}$ seems to be contributing to reduced precision in predicting VFA concentrations. Dijkstra et al. (1993) demonstrated that low ruminal $\mathrm{pH}$ supplied more protons for the conversion of the dissociated VFA to the acid form to facilitate diffusion across the rumen epithelium, leading to increased fractional absorption rates. Currently, this mechanism is not encoded in the model and its absence is consistent with the observed residual errors given the negative correlation between ruminal $\mathrm{pH}$ and residual VFA concentrations.

All VFA residual errors were also negatively correlated with dietary soluble $\mathrm{CP}$, indicating VFA production errors were also driven by protein fermentation and possibly microbial activity in response to RDP and ammonia. Parker et al. (1995) indicated that the exchange of protons between ammonia and VFA might potentially stimulate their absorption rates, implying that directly adding the effect of ammonia on VFA absorption rates or indirectly in the ruminal $\mathrm{pH}$ equation might reduce model errors for VFA concentrations.

Residual errors for all of the VFA were also positively correlated with BW and dietary ash concentrations, suggesting that at high dietary ash concentrations 
ruminal VFA concentrations were underpredicted. Collectively these indicate that the effects of rumen liquid volume and rumen water dynamics on VFA kinetics might be inappropriately predicted. Dietary ash can be elevated due to soil contamination of forages. Mayland and Sneva (1983) found that the sodium concentration of soil was $1,630 \mu \mathrm{g} / \mathrm{g}$, whereas that of forages was $93 \mu \mathrm{g} / \mathrm{g}$, thus dietary sodium and soluble ash content can be influenced by soil contamination. Meyer et al. (2004) indicated dietary sodium intake is positively correlated with water intake, which is consistent with our results, as the increased dietary ash concentrations might stimulate water intake leading to greater liquid outflow and underpredicted VFA concentrations. Water consumption was set at $4.7 \mathrm{~L} / \mathrm{kg}$ of DMI. Although the osmotic effects of ash on rumen water dynamics are incorporated in the model, regression results indicated that this relationship is not well represented, which might reflect lack of knowledge regarding ash solubility and the relationship between osmolarity and fluid movement. The latter was based on the effects of sodium bicarbonate, assuming 2 ions per mole of ash, and osmolality from ash was calculated as moles of ash multiplied by an osmolarity of 1.7 , which might lead to prediction errors as the composition of ash in rumen fluid varies due to entry of other ions including potassium, calcium, magnesium, and chloride. Because the soluble ash molecular weight was assumed to be that of sodium bicarbonate, calculated molarity also can be biased. Finally, as only the soluble fraction of ash affects osmolality and water balance, variation in ash solubility would have contributed to variation in predictions of fluid osmolality given our assumed fixed insolubility proportion (Argyle and Baldwin, 1988). Sorting out these potential effects will require a concerted effort to collect such information across a range of diets.

Ruminal Ammonia Concentrations. Ruminal ammonia concentrations exhibited a RMSE of $49.9 \%$ with $0.1 \%$ of mean bias and $43.7 \%$ of MSE segregating with a negative slope bias (Figure 4 and Table 4). The substantial slope bias implies that mechanisms related to ruminal $\mathrm{N}$ metabolism are improperly represented. Residual errors for ruminal ammonia were negatively related to DMI, dietary concentrations of rumen undegraded NDF, forage NDF, rumen undegraded starch, $\mathrm{CP}, \mathrm{NPN}$, and ruminal $\mathrm{pH}$, and positively related to di-

Table 6. Multivariate regression analyses of residual errors for predicted ruminal and blood metabolites ${ }^{1}$

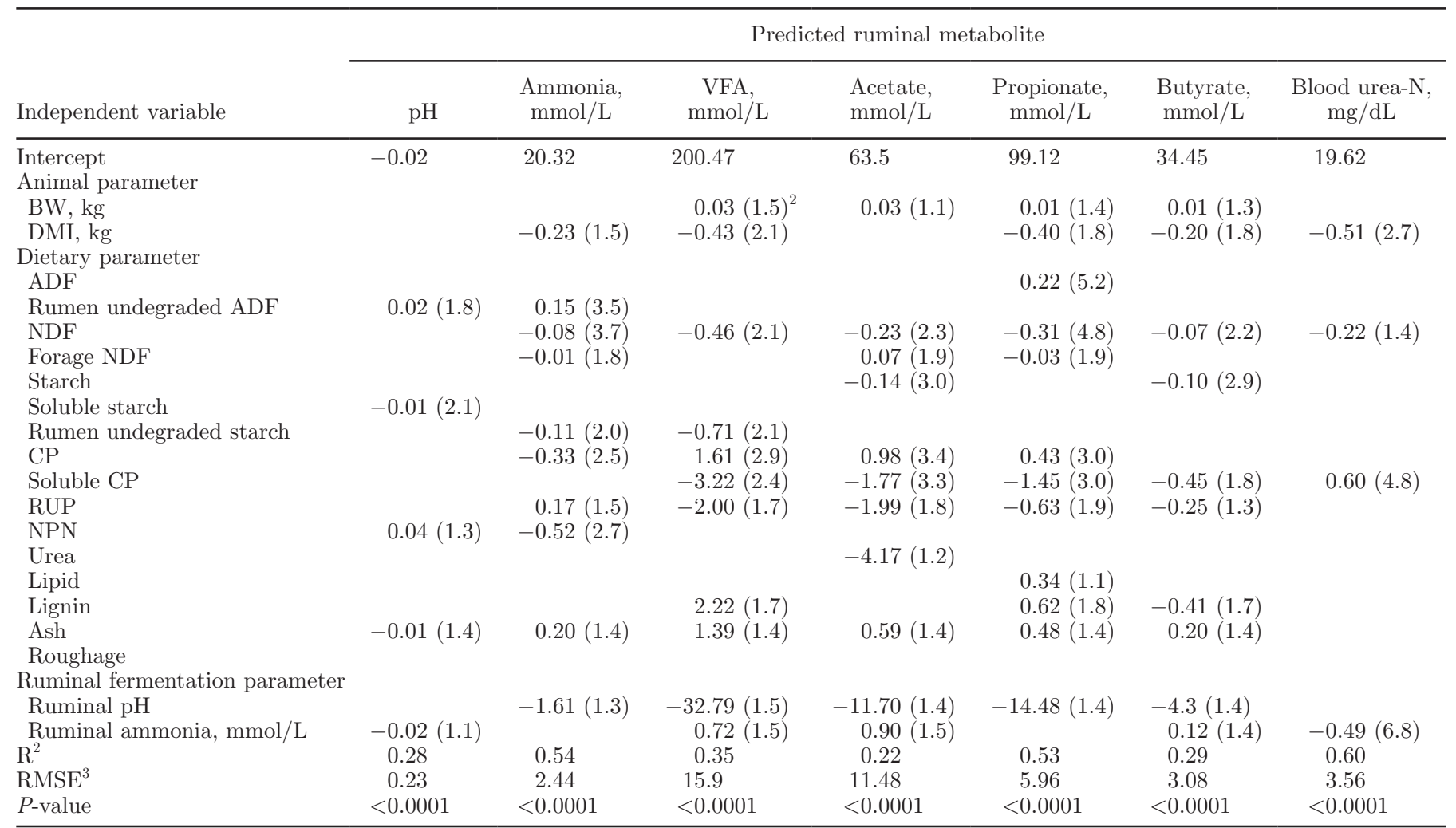

${ }^{1}$ Study effect was included as a random variable.

${ }^{2}$ Independent variables listed were significant $(P<0.1)$. Variance inflation factors are shown in parentheses.

${ }^{3} \mathrm{RMSE}=$ root mean squared error. 
etary concentrations of rumen undegraded ADF, RUP, and ash (Table 6). The positive correlations with dietary RUP and negative correlations with DMI and dietary concentrations of $\mathrm{CP}$ indicates that increased dietary $\mathrm{N}$ intake was associated with overpredicted ruminal ammonia concentrations; or alternatively, increased dietary RUP was associated with underpredicted ammonia concentrations. These errors might suggest that protein degradation rates saturate with protein availability. Alternatively, the correlations might imply that protein sources affect incorporation rates of ammonia $\mathrm{N}$ into microbial N. It seems logical that microbes would obtain a greater proportion of $\mathrm{N}$ from ammonia when high RUP diets were fed due to decreased availability of proteolytic end products; however, that is contrary to the observed correlation and thus does not appear to explain the prediction errors.

The negative correlations between residual errors for ruminal ammonia concentrations and rumen undegraded NDF and rumen undegraded starch, imply that ruminal ammonia residual errors are positively correlated with ruminally fermentable $\mathrm{CHO}$, and ammonia concentrations are underpredicted when cattle are fed highly fermentable $\mathrm{CHO}$ diets and over predicted with high forage diets. Cameron et al. (1991) and Reynolds and Kristensen (2008) indicated that the amount and degradability of dietary $\mathrm{CHO}$ can affect $\mathrm{NH}_{3}$ absorption, given that incorporation of ammonia $\mathrm{N}$ into microbial protein is energy-dependent. Cameron et al. (1991) demonstrated that infusions of readily ferment-

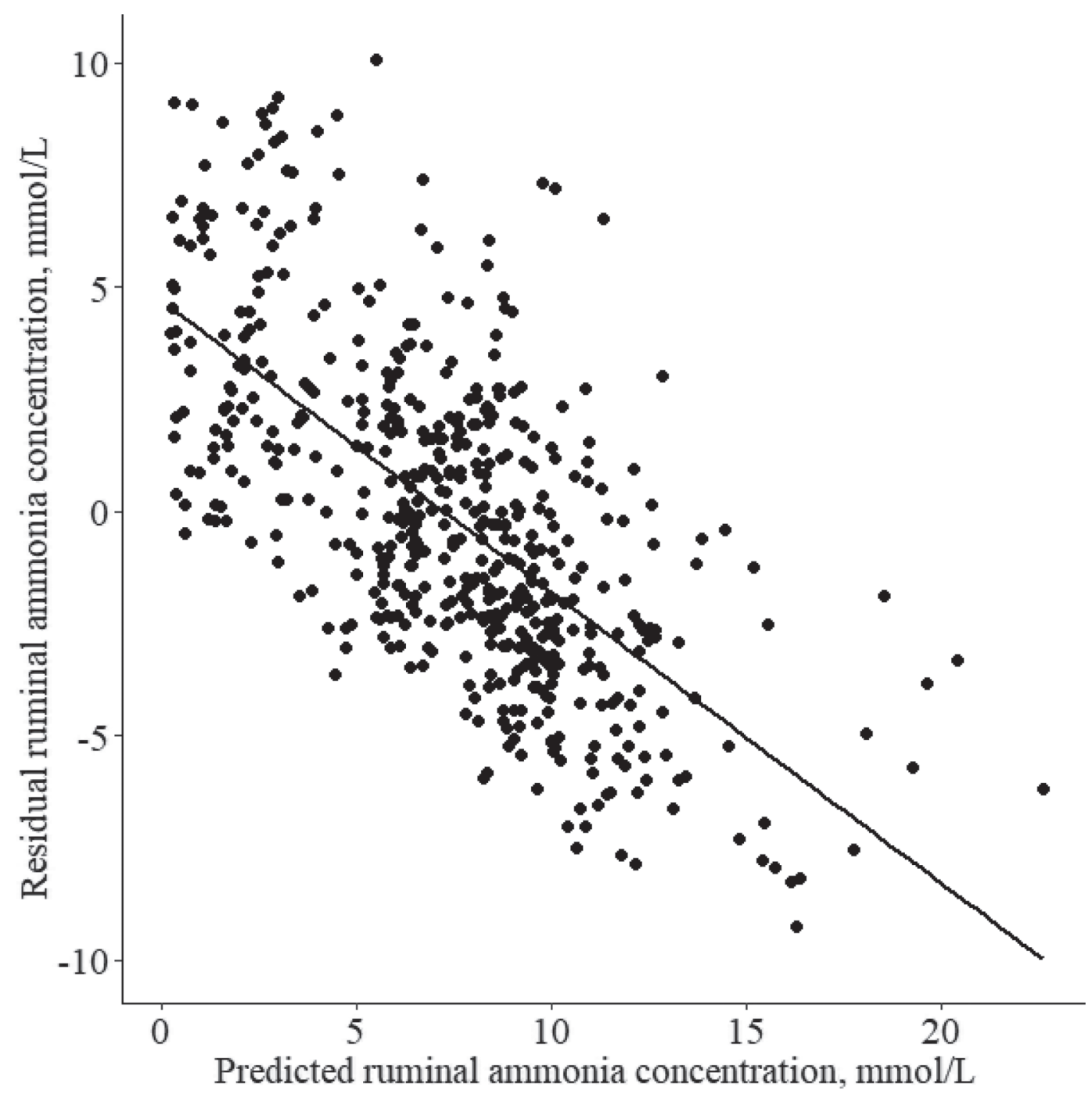

Figure 4. Residual errors for predicted ruminal ammonia concentrations (root mean squared error $=49.9 \%$, mean bias $=0.1 \%$ MSE, slope bias $=43.7 \%$ MSE, $\mathrm{n}=538)$. MSE represents mean squared error. 
able CHO decreased ammonia concentrations because of increased $\mathrm{N}$ uptake by ruminal microbes. Microbial growth predictions appear to contribute to the problem by being over-responsive to fermentable $\mathrm{CHO}$ supply as evidenced by negative correlations between residuals for predictions of ruminal microbial $\mathrm{N}$ outflow and starch intake. Thus, high starch diets would lead to excessive sequestration of ruminal ammonia, which contributes to the problem. However, this does not appear to be the sole contributor.

Blood Urea-N Concentrations. Predictions of blood urea-N concentrations had a RMSE of $51.8 \%$ with $28.8 \%$ mean bias and $33.5 \%$ negative slope bias (Figure 5 and Table 4). Residuals of blood urea-N concentrations were negatively correlated with DMI, dietary NDF concentrations, and ruminal ammonia concentra- tions (Figure 6), and positively correlated with dietary soluble protein concentrations (Table 6). The negative correlation between residual blood urea- $\mathrm{N}$ concentrations and DMI indicates that blood urea-N concentrations are overpredicted with high DMI, possibly related to high BW (Clauss et al., 2007). Urinary urea excretion is calculated in the model as the product of blood urea concentrations $(\mathrm{mol} / \mathrm{L})$ and a fixed excretion constant of 2,134 L/d (Baldwin, 1995), implying that the excretion rate constant of a small animal is the same as a large animal at equal blood urea concentrations. This appears to be an oversight in model construction as kidney clearance will be a function of concentration and body mass reflecting the greater blood flow and kidney mass in a larger animal. Most functions in the model that must scale with $\mathrm{BW}$ are defined using the

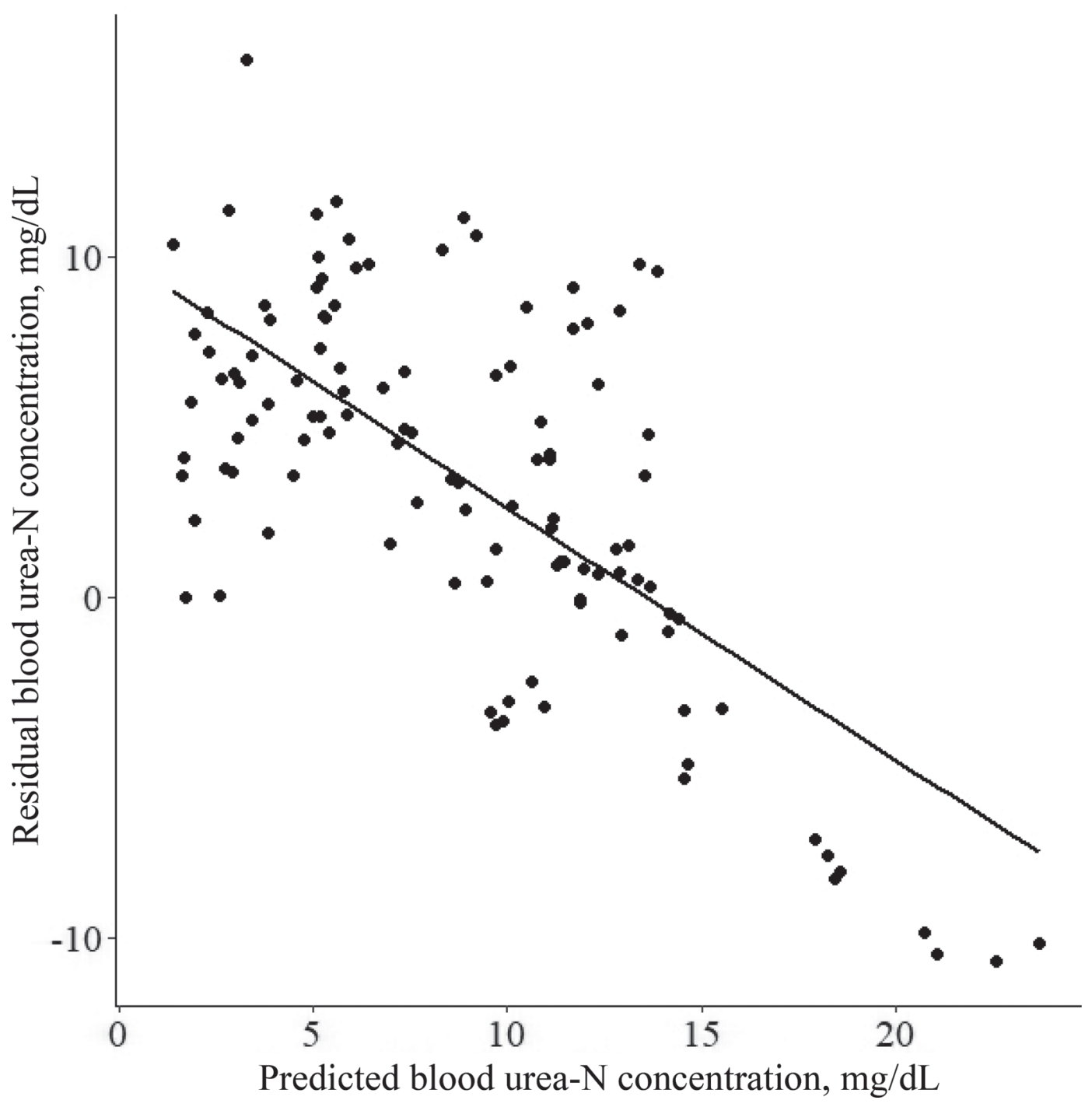

Figure 5. Residual errors for predicted blood urea-N concentrations (root mean squared error $=51.8 \%$, mean bias $=28.8 \%$ MSE, slope bias $=33.5 \%$ MSE, $\mathrm{n}=114$ ). MSE represents mean squared error. 
pool size, which will scale with BW, rather than with a concentration, hence our assumption that this was an oversight by whomever added the representation. Modifying the existing urinary urea secretion equation to use blood urea pool size that scales with BW would increase the accuracy of model predictions of blood urea- $\mathrm{N}$ and might help address the rumen ammonia problem given the correlation among these 2 variables.

The negative correlation between blood urea- $\mathrm{N}$ residuals and ruminal ammonia concentrations suggests that increased ammonia concentrations are correlated with over predictions of blood urea-N. Reynolds and Kristensen (2008) demonstrated substantial N cycling between the blood urea and gut lumen ammonia pools. High rates of cycling confer greater response flexibility within the system. For example, if the rate of cycling between 2 pools is $100 \% / d$, a $50 \%$ change in the first pool and no change in the size of the 2 nd pool will result in a $40 \%$ change in the net difference between the fluxes. However, if all else is held constant and the cycling rate is increased to $200 \% / \mathrm{d}$, the net cycling difference caused by the change in size of the first pool will increase to $80 \%$. Thus, accumulation of $\mathrm{N}$ in either the ruminal ammonia or the blood urea pools with insufficient responses in the other pool is an indication that the rate of cycling is too low. With too low of cycling rates, increased intake of soluble $\mathrm{N}$ would lead to greater than expected changes in ruminal ammonia as the net difference in the rates of transfer between the ruminal and blood pools would not be great enough to buffer the increase in ruminal ammonia. In this case, blood urea concentrations would be underpredicted. Increased rates of cycling between ruminal ammonia and blood urea would dampen ruminal ammonia con-

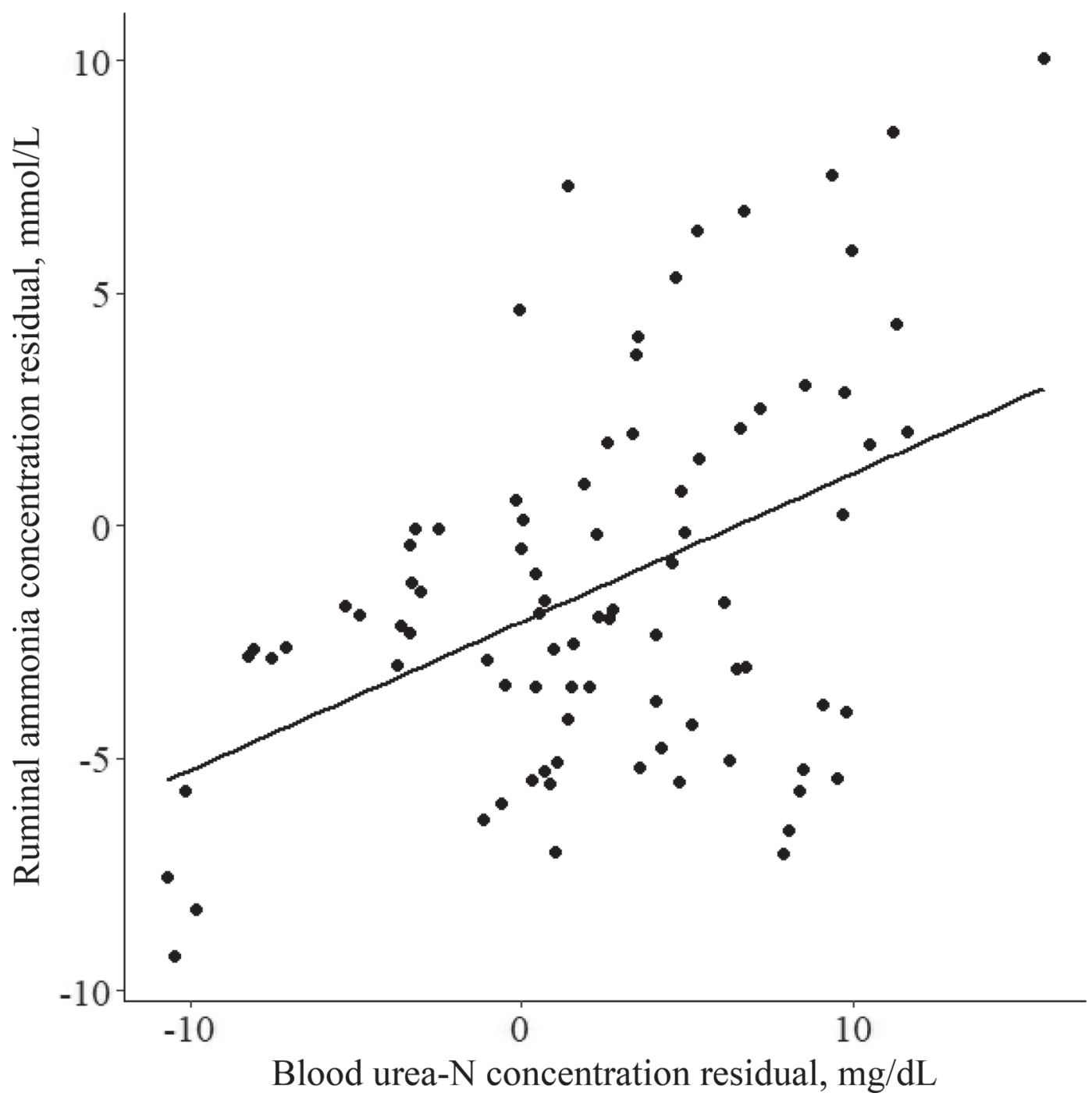

Figure 6. Ruminal ammonia concentration residuals versus blood urea-N concentration residuals. 
Table 7. Simple linear regression analyses of residual errors for predicted fecal outputs

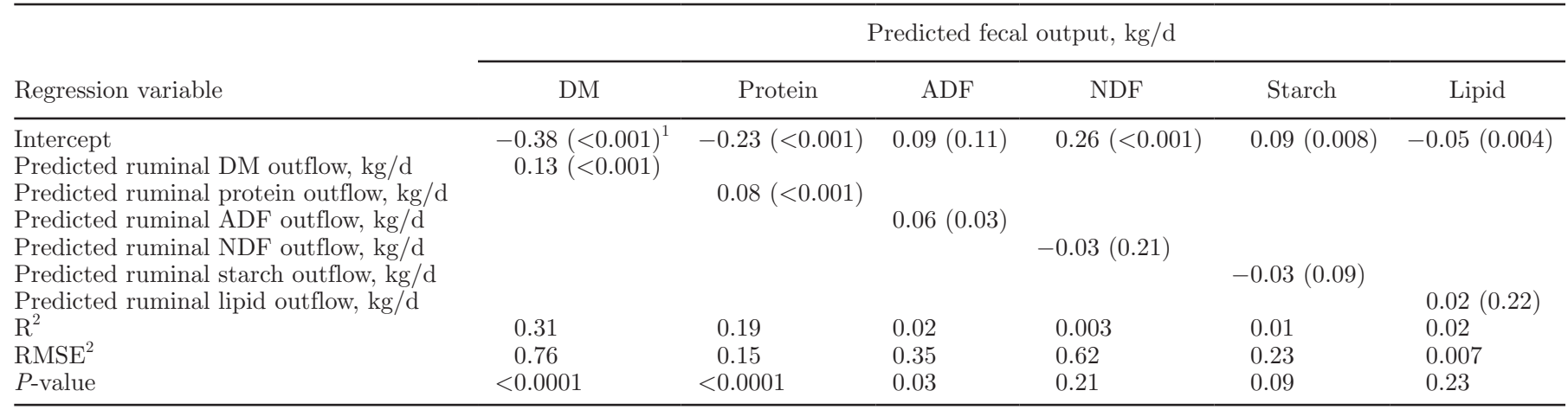

${ }^{1} P$-value is shown in parentheses.

${ }^{2} \mathrm{RMSE}=$ root mean squared error.

centration changes and enhance blood urea changes in response to ruminal $\mathrm{N}$ load. Based on concentration changes only, one would be able to derive minimal cycling rates, but not maximal as further increases above the minimum would result in identical concentrations. An exact solution would require fitting to ammonia absorption and urea transfer data derived from isotope experiments such as those using the double-labeled urea approach (Reynolds and Kristensen, 2008; Wickersham et al., 2008a, 2008b, 2009; Bailey et al., 2012; Batista et al., 2016).

\section{Fecal Output}

Fecal DM, ADF, NDF, and Lipid Excretion. Residual errors of predicted fecal DM and ADF excretion were 24.9 and $21.5 \%$ with on average $37 \%$ mean bias and $8 \%$ slope bias. Predicted fecal output of NDF and lipid had RMSE of 22.8 and $31.8 \%$ with on average $14 \%$ mean bias and $1 \%$ slope bias (Table 4). Fecal $\mathrm{DM}$ and $\mathrm{ADF}$ excretion were positively correlated with their predicted ruminal outflow (Table 7). Thus, as ruminal outflow increased, fecal DM and ADF output are underpredicted, suggesting an ADF digestion coefficient of 0.118 is an overestimate (Hanigan et al., 2013). Residual errors of fecal NDF and lipid outflow were not significantly correlated with their ruminal outflow, indicating prediction errors for fecal NDF and lipid outflow are not driven by encoded digestion coefficients. Further analyses indicated residual errors for fecal output of DM, ADF, and NDF were all negatively correlated with $\mathrm{BW}$, with overpredictions at high $\mathrm{BW}$, and underpredictions at low BW. In the current work, BW ranged from 240 to $807 \mathrm{~kg}$, which is wider than the range of 480 to $731 \mathrm{~kg}$ in the data used by Hanigan et al. (2013). Digestive efficiency can be modeled as the result of an interplay of gut capacity, feed intake, and digesta passage (Clauss et al., 2007). Of these, capacity is at least partially dictated by BW. Because intestinal digestibility is represented solely as mass action functions of ruminal outflow in the model, correlations between BW and fecal nutrient residual errors likely reflect the lack of a representation of maximal capacity (Ellis et al., 2014) and indicate that adding BW as an effector of intestinal digestibility would improve model performance with respect to lower gut nutrient digestion.

Fecal Starch Excretion. Predicted fecal starch excretion had a RMSE of $73.4 \%$ (2.8\% mean bias and $1 \%$ slope bias) and a CCC of 0.35 , suggesting relatively poor prediction quality (Table 4). However, starch digestion occurs predominantly in the rumen and is nearly complete in the total tract. Thus predicting fecal starch excretion is subject to considerable relative error as the mass is relatively small. Residual errors of fecal starch excretion tended to be negatively correlated with predicted ruminal starch outflow $(P=0.09$; Table 7 ), suggesting fecal starch excretion is overpredicted with increased ruminal starch outflow. Because there is no slope bias in the predictions, this suggests the cause of a portion of the fecal starch error are errors in predicting ruminal starch outflow. Because the model uses a fixed digestion coefficient of 0.81 to simulate lower gut digestion (Hanigan et al., 2013), optimizing the digestion coefficient will not address the prediction errors. Additional progress in predicting intestinal digestibility may require alternative representations such as the more complicated mechanistic model of Mills et al. (2017).

Fecal Protein Excretion. Residual errors for fecal protein excretion exhibited a RMSE of $18 \%$ (0.1\% mean bias and $19 \%$ slope bias) and a CCC of 0.89 (Table 4). Ruminal $\mathrm{N}$ outflow had a slight mean bias and slope bias, which will contribute to fecal error. Residual fecal output errors were positively correlated with predicted ruminal protein outflow (Table 7 ), indicating that fecal 
protein output is underpredicted when ruminal protein outflow is high. This implies that intestinal protein digestion is less efficient at high protein flow than predicted with the current static digestion coefficient. The model does not consider endogenous protein secretion into the lower gut, but this should result in the opposite problem as the apparent digestion coefficient should increase with greater protein flow.

\section{Evaluations by Cattle Category and Diet Type}

Cattle Category. Dairy and beef data were evaluated separately to assess differences between animal type with respect to predictive capacity of the model. Residual analyses indicated that all variables related to ruminal metabolism and nutrient digestion were predicted with lesser RMSE for dairy cattle than for beef cattle (Table 8 ). The model was originally designed to represent biological elements of the dairy cow (Baldwin et al., 1987a,b,c). It has been modified and advanced using primarily dairy data, thus it is to be expected that the model performed better when simulating moderate forage diets typical of those fed to dairy cattle. Root mean squared errors for predictions of ruminal nutrient outflow (total N, microbial N, and NAN), fecal nutrient excretion (protein, NDF, and lipid), ruminal $\mathrm{pH}$, and ammonia, acetate, propionate, butyrate, and blood urea-N concentrations were much greater for beef data than for dairy data (Table 8), primarily due to mean biases, suggesting that prediction accuracy could be improved through optimization of model parameters. Substantial slope biases for ruminal outflow of ADF, $\mathrm{NDF}$, starch, total $\mathrm{N}$, and microbial $\mathrm{N}$ were observed when beef data were simulated. Regression analyses of residuals indicated that BW was negatively correlated with errors of prediction for ruminal outflow of ADF, NDF, starch, and microbial N, whereas DMI was positively correlated with residuals for ruminal outflow of DM, starch, and microbial N (Table 5). These suggest that the combinations of BW and DMI might have contributed to accuracy and precision problems for these variables. When DMI was expressed per kilogram of $\mathrm{BW}$, the mean was $0.03 \mathrm{~kg} / \mathrm{kg}$ of BW for dairy cattle and $0.02 \mathrm{~kg} / \mathrm{kg}$ of BW for beef cattle. One would thus expect greater digestive efficiency for the beef cattle than for dairy cattle due to digestibility depression as DMI increases (Clauss et al., 2007). The current model represents greater ruminal outflow as DMI increases,

Table 8 . Model evaluations by cattle category ${ }^{1}$

\begin{tabular}{|c|c|c|c|c|c|c|c|c|c|c|}
\hline \multirow[b]{2}{*}{ Items } & \multicolumn{2}{|c|}{$\mathrm{n}$} & \multicolumn{2}{|c|}{$\mathrm{RMSE}^{2} \%$ mean } & \multicolumn{2}{|c|}{ Mean bias, $\% \mathrm{MSE}^{3}$} & \multicolumn{2}{|c|}{ Slope bias, \% MSE } & \multicolumn{2}{|c|}{$\mathrm{CCC}^{4}$} \\
\hline & Dairy & Beef & Dairy & Beef & Dairy & Beef & Dairy & Beef & Dairy & Beef \\
\hline \multicolumn{11}{|l|}{ Ruminal outflow, kg/d } \\
\hline $\mathrm{ADF}$ & 204 & 21 & 24.9 & 44.6 & $29.5^{*}$ & 5.0 & 1.1 & $22.1^{*}$ & 0.65 & 0.56 \\
\hline NDF & 299 & 43 & 25.6 & 27.8 & $13.7^{*}$ & 0.5 & $1.7^{*}$ & $20.2^{*}$ & 0.6 & 0.66 \\
\hline Starch & 180 & 45 & 56.7 & 82.8 & $29.4^{*}$ & $11.7^{*}$ & 0.1 & $54.0^{*}$ & 0.29 & 0.002 \\
\hline Total N & 440 & 70 & 18.1 & 39.1 & $7.9^{*}$ & $20.1^{*}$ & 0.3 & $32.1^{*}$ & 0.74 & 0.29 \\
\hline Microbial N & 557 & 68 & 29.1 & 57.0 & $18.4^{*}$ & $19.3^{*}$ & 0.5 & $34.0^{*}$ & 0.56 & 0.13 \\
\hline NAN & 540 & 26 & 18.6 & 58.9 & 0.2 & $59.1^{*}$ & $1.9^{*}$ & $11.2^{*}$ & 0.75 & 0.09 \\
\hline $\mathrm{NANMN}^{5}$ & 536 & 24 & 39.9 & 40.7 & $25.7^{*}$ & 0.4 & $0.8^{*}$ & 1.0 & 0.38 & 0.57 \\
\hline \multicolumn{11}{|c|}{ Ruminal fermentation parameter } \\
\hline $\mathrm{pH}$ & 452 & 159 & 4.1 & 6.0 & $6.5^{*}$ & $9.6^{*}$ & 0.003 & 0.4 & 0.04 & 0.03 \\
\hline Ammonia, mmol/L & 430 & 108 & 44.9 & 67.4 & $10.1^{*}$ & $55.9^{*}$ & $26.6^{*}$ & $11.2^{*}$ & 0.46 & 0.27 \\
\hline $\mathrm{VFA}, \mathrm{mmol} / \mathrm{L}$ & 430 & 154 & 16.9 & 27.0 & $3.7^{*}$ & $18.5^{*}$ & $3.2^{*}$ & 1.5 & 0.23 & 0.25 \\
\hline Acetate, $\mathrm{mmol} / \mathrm{L}$ & 432 & 166 & 18.4 & 23.8 & 0.3 & 0.9 & $2.5^{*}$ & $8.4^{*}$ & 0.16 & 0.26 \\
\hline Propionate, mmol/L & 432 & 160 & 28 & 48.7 & $7.8^{*}$ & $22.5^{*}$ & $2.6^{*}$ & 0.9 & 0.21 & 0.21 \\
\hline Butyrate, mmol/L & 432 & 160 & 24.2 & 39.5 & $1.2^{*}$ & $16.0^{*}$ & $5.7^{*}$ & 1.9 & 0.17 & 0.17 \\
\hline Blood urea-N, mg/dL & 74 & 40 & 44 & 65.3 & $5.6^{*}$ & $90.5^{*}$ & $37.8^{*}$ & $2.8^{*}$ & 0.25 & 0.16 \\
\hline \multicolumn{11}{|l|}{ Fecal outflow, kg } \\
\hline DM & 255 & 136 & 22.7 & 30.4 & $65.4^{*}$ & $19.3^{*}$ & $2.2^{*}$ & $15.3^{*}$ & 0.58 & 0.61 \\
\hline $\mathrm{OM}$ & 389 & 138 & 24.8 & 29.9 & $56.9^{*}$ & $5.9^{*}$ & $0.8^{*}$ & $11.0^{*}$ & 0.59 & 0.71 \\
\hline Protein & 372 & 128 & 15.7 & 39.3 & $3.5^{*}$ & $39.6^{*}$ & $10.6^{*}$ & 0.04 & 0.81 & 0.61 \\
\hline $\mathrm{ADF}$ & 186 & 57 & 19.6 & 35.5 & $30.9^{*}$ & 6.3 & 0.2 & 3.6 & 0.75 & 0.72 \\
\hline $\mathrm{NDF}$ & 333 & 112 & 19.7 & 44.7 & $6.2^{*}$ & $11.0^{*}$ & 1.0 & $3.7^{*}$ & 0.72 & 0.57 \\
\hline Lipid & 53 & 25 & 23.5 & 84.9 & $12.9^{*}$ & $36.6^{*}$ & 1.6 & $10.1^{*}$ & 0.84 & 0.32 \\
\hline Starch & 156 & 105 & 64.8 & 95.9 & $7.3^{*}$ & 0.5 & $4.9^{*}$ & $10.7^{*}$ & 0.17 & 0.18 \\
\hline
\end{tabular}

${ }^{1}$ Ruminal DM outflow was not reported because of limited observations.

${ }^{2} \mathrm{RMSE}=$ root mean squared error.

${ }^{3} \mathrm{MSE}=$ mean squared error.

${ }^{4} \mathrm{CCC}=$ concordance correlation coefficient.

${ }^{5} \mathrm{NANMN}=$ nonammonia, nonmicrobial $\mathrm{N}$.

* denotes the model bias is significantly different from $0(P<0.05)$. 
but it does not represent reduced ruminal residence time which would alter the extent of digestion. The regressions suggest that the relative DMI should be used to regulate ruminal passage rates so that greater DMI relative to $\mathrm{BW}$ causes a reduction in ruminal digestibility.

Diet Type. The nutrient composition of beef cattle diets vary more than dairy cattle diets, due primarily to different feeding scenarios (Ellis et al., 2007). Descriptive statistics show that the mean forage percentage for dairy diets was $51.8 \%$ with a standard deviation of $13.4 \%$, whereas it was $29.3 \%$ with a standard deviation of $32.1 \%$ for beef cattle diets. High-forage and low-forage diets are more commonly used for beef animals, and limited evaluations of the model have been conducted with such diets. When simulating nutrient digestion and ruminal metabolism for high and low forage diets (Table 9), the average RMSE was approximately $5 \%$ units greater than for the combined data or when compared with the dairy data, which was composed almost completely of moderate forage diets (Table 4). Based on the results of RMSE and CCC, the model tended to more accurately predict ruminal metabolism and nutrient flows for high forage diets than low forage diets, except for ruminal outflow of ADF, NDF, and microbial N (Table 9). However, there was greater slope bias for ammonia and blood urea-N concentrations; and ruminal outflow of ADF, NDF, starch, and microbial N when simulating high forage diets. In the model, empirical equations were used to represent the relationship between forage percentage and particle size, and the model simulates 3 particle size pools with homogeneous nutrient content to simulate ruminal digesta outflow. This latter simplification might introduce some error as the large particle pool likely includes more fiber and less starch than the small particle pool. As the pools have different rates of passage, the residence time of starch might be overpredicted and that of fiber underpredicted, which could lead to the observed errors of prediction. In the current study, the model underpredicted ruminal starch outflow and overpredicted ADF and NDF outflow when it was evaluated using high forage diets. The opposite was observed when the model was assessed with low forage diets. These biases equate to an overprediction of ruminal starch digestion and an underprediction ruminal fiber digestion on high forage diets, which is consistent with the potential bias in representation of residence time. However, these

Table 9. Model evaluations by diet type ${ }^{1}$

\begin{tabular}{|c|c|c|c|c|c|c|c|c|c|c|}
\hline \multirow[b]{2}{*}{ Items } & \multicolumn{2}{|c|}{$\mathrm{n}$} & \multicolumn{2}{|c|}{$\mathrm{RMSE}^{2} \%$ mean } & \multicolumn{2}{|c|}{ Mean bias, $\%$ MSE $^{3}$} & \multicolumn{2}{|c|}{ Slope bias, \% MSE } & \multicolumn{2}{|c|}{$\mathrm{CCC}^{4}$} \\
\hline & High & Low & High & Low & High & Low & High & Low & High & Low \\
\hline \multicolumn{11}{|l|}{ Ruminal outflow, $\mathrm{kg} / \mathrm{d}$} \\
\hline DM & 8 & 13 & 16.6 & 16.6 & 1.9 & 3.6 & $37.5^{*}$ & $38.5^{*}$ & 0.92 & 0.84 \\
\hline $\mathrm{ADF}$ & 12 & 18 & 34.5 & 25.8 & 3.4 & $47.5^{*}$ & $58.4^{*}$ & $12.7^{*}$ & 0.42 & 0.91 \\
\hline NDF & 23 & 29 & 37.4 & 21.8 & 8.3 & 5.5 & $40.9^{*}$ & $12.0^{*}$ & 0.73 & 0.93 \\
\hline Starch & 2 & 37 & 10.0 & 74.1 & $32.9^{*}$ & 6.8 & $67.1^{*}$ & $18.7^{*}$ & 0.99 & 0.38 \\
\hline Nonammonia N & 32 & 36 & 20.8 & 30.3 & 0.005 & 9.1 & 4.4 & $22.1^{*}$ & 0.72 & 0.85 \\
\hline NANMN $^{5}$ & 35 & 31 & 32 & 36.2 & $21.3^{*}$ & $14.2^{*}$ & 0.02 & $14.7^{*}$ & 0.7 & 0.83 \\
\hline \multicolumn{11}{|c|}{ Ruminal fermentation parameter } \\
\hline $\mathrm{pH}$ & 58 & 92 & 4.9 & 6.7 & $59.4^{*}$ & $54.5^{*}$ & $4.6^{*}$ & $3.3^{*}$ & 0.14 & -0.01 \\
\hline Ammonia, $\mathrm{mmol} / \mathrm{L}$ & 54 & 65 & 52.2 & 66.8 & 4.3 & $68.3^{*}$ & $40.1^{*}$ & $5.4^{*}$ & 0.75 & 0.20 \\
\hline VFA, mmol/L & 62 & 85 & 22.0 & 28.1 & 2.4 & $41.9^{*}$ & 0.8 & $4.2^{*}$ & 0.60 & 0.10 \\
\hline Acetate, $\mathrm{mmol} / \mathrm{L}$ & 62 & 101 & 24.2 & 27.1 & 1.8 & 2.4 & 0.01 & $17.1^{*}$ & 0.45 & 0.01 \\
\hline $\mathrm{OM}$ & 36 & 100 & 29.8 & 31.1 & $23.0^{*}$ & 3.3 & 0.6 & $37.1^{*}$ & 0.78 & 0.88 \\
\hline Protein & 30 & 98 & 19.3 & 36.2 & 2.1 & $25.1^{*}$ & 0.2 & $18.7^{*}$ & 0.94 & 0.8 \\
\hline $\mathrm{ADF}$ & 15 & 38 & 27.4 & 32.4 & $61.9^{*}$ & $23.9^{*}$ & $22.9^{*}$ & $63.2^{*}$ & 0.74 & 0.93 \\
\hline NDF & 39 & 73 & 41.0 & 33.6 & 0.004 & $9.4^{*}$ & $16.6^{*}$ & 0.03 & 0.66 & 0.89 \\
\hline
\end{tabular}

${ }^{1}$ High forage diet: forage percentage $>70 \%$; low forage diet: forage percentage $<30 \%$. Fecal lipid and starch output were not reported because of limited observations.

${ }^{2} \mathrm{RMSE}=$ root mean squared error.

${ }^{3} \mathrm{MSE}=$ mean squared error.

${ }^{4} \mathrm{CCC}=$ concordance correlation coefficient.

${ }^{5} \mathrm{NANMN}=$ nonammonia, nonmicrobial $\mathrm{N}$.

* denotes the model bias is significantly different from $0(P<0.05)$. 
problems could also reflect the challenges with predicting $\mathrm{pH}$ and ruminal ammonia concentrations and the effect on microbial activity. Additional basic metabolic data characterizing the underlying biology is needed to discriminate among these hypotheses and correct the prediction problems.

\section{CONCLUSIONS}

In summary, the Molly model performed relatively well on diets with moderate levels of forage except for predictions of ruminal $\mathrm{pH}$, ruminal ammonia concentrations, which exhibited significant slope bias, and ruminal outflow of starch and NANMN, which had poor precision. However, the model performed more poorly on diets with extreme concentrations of forage, although the number of diets represented in those categories was more limited, and thus subject to less certainty. Model weakness requiring improvements appeared to be related to predictions of ruminal $\mathrm{pH}$ and $\mathrm{N}$ cycling across the ruminal wall, and digestibility depressions associated with high intakes relative to BW. Residual analyses identified ruminal ammonia concentrations as a factor contributing to ruminal $\mathrm{pH}$ prediction errors. Incorporation of the concept of a maximal digestive capacity in the rumen and intestine also merits consideration to improve predictions of ruminal outflow, ruminal fermentation, and fecal output. Adoption of these changes should yield a model that provides unbiased predictions of nutrient digestion across the full range of cattle diets used in North America.

\section{ACKNOWLEDGMENTS}

This work was funded, in part, by the Virginia Agricultural Experiment Station and the Hatch Program of the National Institute of Food and Agriculture, US Department of Agriculture; the College of Agriculture and Life Sciences Pratt Endowment at Virginia Tech, and the Alberta Livestock and Meat Agency Ltd. (grant 2015F055R; Edmonton, Alberta, Canada).

\section{REFERENCES}

Abdoun, K., F. Stumpff, and H. Martens. 2006. Ammonia and urea transport across the rumen epithelium: A review. Anim. Health Res. Rev. 7:43-59.

Argyle, J., and R. Baldwin. 1988. Modeling of rumen water kinetics and effects of rumen $\mathrm{pH}$ changes. J. Dairy Sci. 71:1178-1188.

Bach, A., S. Calsamiglia, and M. Stern. 2005. Nitrogen metabolism in the rumen. J. Dairy Sci. 88:E9-E21.

Bailey, E., E. Titgemeyer, K. Olson, D. Brake, M. Jones, and D. Anderson. 2012. Effects of ruminal casein and glucose on forage digestion and urea kinetics in beef cattle. J. Anim. Sci. 90:3505-3514.

Baldwin, R. 1995. Modeling Ruminant Digestion and Metabolism. Springer Science \& Business Media, Berlin, Germany.
Baldwin, R. L., J. France, D. E. Beever, M. Gill, and J. H. Thornley 1987a. Metabolism of the lactating cow: III. Properties of mechanistic models suitable for evaluation of energetic relationships and factors involved in the partition of nutrients. J. Dairy Res. $54: 133-145$

Baldwin, R. L., J. France, and M. Gill. 1987b. Metabolism of the lactating cow: I. Animal elements of a mechanistic model. J. Dairy Res. 54:77-105.

Baldwin, R. L., J. H. Thornley, and D. E. Beever. 1987c. Metabolism of the lactating cow: II. Digestive elements of a mechanistic model. J. Dairy Res. 54:107-131.

Batista, E., E. Detmann, E. C. Titgemeyer, S. Valadares Filho, R. Valadares, L. Prates, L. Rennó, and M. Paulino. 2016. Effects of varying ruminally undegradable protein supplementation on forage digestion, nitrogen metabolism, and urea kinetics in Nellore cattle fed low-quality tropical forage. J. Anim. Sci. 94:201-216.

Bibby, J., and H. Toutenburg. 1977. Prediction and Improved Estimation in Linear Models. Wiley, Chichester, UK.

Briggs, P., J. Hogan, and R. Reid. 1957. Effect of volatile fatty acids, lactic acid and ammonia on rumen $\mathrm{pH}$ in sheep. Crop Pasture Sci. 8:674-690

Cameron, M., T. Klusmeyer, G. Lynch, J. Clark, and D. Nelson. 1991. Effects of urea and starch on rumen fermentation, nutrient passage to the duodenum, and performance of cows. J. Dairy Sci $74: 1321-1336$.

Cecava, M., N. Merchen, L. Berger, R. Mackie, and G. Fahey. 1991 Effects of dietary energy level and protein source on nutrient digestion and ruminal nitrogen metabolism in steers. J. Anim. Sci. 69:2230-2243.

Clauss, M., A. Schwarm, S. Ortmann, W. J. Streich, and J. Hummel. 2007. A case of non-scaling in mammalian physiology? Body size, digestive capacity, food intake, and ingesta passage in mammalian herbivores. Comp. Biochem. Physiol. A Mol. Integr. Physiol 148:249-265.

Craney, T. A., and J. G. Surles. 2002. Model-dependent variance inflation factor cutoff values. Qual. Eng. 14:391-403.

Dijkstra, J., H. Boer, J. Van Bruchem, M. Bruining, and S. Tamminga. 1993. Absorption of volatile fatty acids from the rumen of lactating dairy cows as influenced by volatile fatty acid concentration, $\mathrm{pH}$ and rumen liquid volume. Br. J. Nutr. 69:385-396.

Dijkstra, J., J. Ellis, E. Kebreab, A. Strathe, S. López, J. France, and A. Bannink. 2012. Ruminal pH regulation and nutritional consequences of low pH. Anim. Feed Sci. Technol. 172:22-33.

Ellis, J., J. Dijkstra, A. Bannink, E. Kebreab, S. Archibeque, C. Benchaar, K. Beauchemin, J. Nkrumah, and J. France. 2014. Improving the prediction of methane production and representation of rumen fermentation for finishing beef cattle within a mechanistic model. Can. J. Anim. Sci. 94:509-524.

Ellis, J., E. Kebreab, N. Odongo, B. McBride, E. Okine, and J. France. 2007. Prediction of methane production from dairy and beef cattle. J. Dairy Sci. 90:3456-3466.

Endres, M., and M. Stern. 1993. Effects of $\mathrm{pH}$ and diets containing various levels of lignosulfonate-treated soybean meal on microbial fermentation in continuous culture. J. Dairy Sci. 76(Suppl 1):177.

Ghimire, S., P. Gregorini, and M. D. Hanigan. 2014. Evaluation of predictions of volatile fatty acid production rates by the Molly cow model. J. Dairy Sci. 97:354-362.

Gregorini, P., P. Beukes, G. Waghorn, D. Pacheco, and M. Hanigan. 2015. Development of an improved representation of rumen digesta outflow in a mechanistic and dynamic model of a dairy cow, Molly. Ecol. Modell. 313:293-306.

Griswold, K., G. Apgar, J. Bouton, and J. Firkins. 2003. Effects of urea infusion and ruminal degradable protein concentration on microbial growth, digestibility, and fermentation in continuous culture. J. Anim. Sci. 81:329-336.

Hanigan, M. 2005. Quantitative aspects of ruminant predicting animal performance. Anim. Sci. 80:23-32.

Hanigan, M. D., J. A. Appuhamy, and P. Gregorini. 2013. Revised digestive parameter estimates for the Molly cow model. J. Dairy Sci. 96:3867-3885. 
Hanigan, M. D., C. C. Palliser, and P. Gregorini. 2009. Altering the representation of hormones and adding consideration of gestational metabolism in a metabolic cow model reduced prediction errors. J. Dairy Sci. 92:5043-5056.

Holt, N., and F. Sosulski. 1981. Nonprotein nitrogen contents of some grain legumes. Can. J. Plant Sci. 61:515-523.

Huhtanen, P., S. Ahvenjärvi, G. Broderick, S. Reynal, and K. Shingfield. 2010. Quantifying ruminal digestion of organic matter and neutral detergent fiber using the omasal sampling technique in cattle-A meta-analysis. J. Dairy Sci. 93:3203-3215.

Huntington, G., and S. Archibeque. 2000. Practical aspects of urea and ammonia metabolism in ruminants. J. Anim. Sci. 77(E. Suppl.):1-11.

Johnson, H. A., and R. L. Baldwin. 2008. Evaluating model predictions of partitioning nitrogen excretion using the dairy cow model Molly. Anim. Feed Sci. Technol. 143:104-126.

Kohn, R., and M. Allen. 1995. In vitro protein degradation of feeds using concentrated enzymes extracted from rumen contents. Anim. Feed Sci. Technol. 52:15-28.

Kononoff, P., and A. Heinrichs. 2003. The effect of corn silage particle size and cottonseed hulls on cows in early lactation. J. Dairy Sci. $86: 2438-2451$.

Kononoff, P., A. Heinrichs, and H. Lehman. 2003. The effect of corn silage particle size on eating behavior, chewing activities, and rumen fermentation in lactating dairy cows. J. Dairy Sci. 86:3343-3353.

Lane, G., C. Noller, V. Colenbrander, K. Cummings, and R. Harrington. 1968. Apparatus for obtaining ruminoreticular samples and the effect of sampling location on $\mathrm{pH}$ and volatile fatty acids. J. Dairy Sci. 51:114-116.

Lin, L. I. 1989. A concordance correlation coefficient to evaluate reproducibility. Biometrics 45:255-268.

Lofgreen, G., J. Hull, and K. K. Otagaki. 1962. Estimation of empty body weight of beef cattle. J. Anim. Sci. 21:20-24.

Maulfair, D., M. Fustini, and A. Heinrichs. 2011. Effect of varying total mixed ration particle size on rumen digesta and fecal particle size and digestibility in lactating dairy cows. J. Dairy Sci. 94:3527-3536.

Maulfair, D., and A. Heinrichs. 2013. Effects of varying forage particle size and fermentable carbohydrates on feed sorting, ruminal fermentation, and milk and component yields of dairy cows. J. Dairy Sci. 96:3085-3097.

Mayland, H., and F. Sneva. 1983. Effect of soil contamination on the mineral composition of forage fertilized with nitrogen. J. Range Manage. 36:286-288.

Meyer, U., M. Everinghoff, D. Gädeken, and G. Flachowsky. 2004. Investigations on the water intake of lactating dairy cows. Livest. Prod. Sci. 90:117-121.

Miller-Webster, T., and W. Hoover. 1998. Nutrient analysis of feedstuffs including carbohydrates. Anim. Sci. Report No. 1. West Virginia Univ., Morgantown.

Mills, J., J. France, J. Ellis, L. Crompton, A. Bannink, M. Hanigan, and J. Dijkstra. 2017. A mechanistic model of small intestinal starch digestion and glucose uptake in the cow. J. Dairy Sci. 100:4650-4670.

Murphy, M., R. Baldwin, and L. Koong. 1982. Estimation of stoichiometric parameters for rumen fermentation of roughage and concentrate diets. J. Anim. Sci. 55:411-421.
NRC. 2001. Nutrient requirements of dairy cattle. 7th ed. National Academy Press, Washington, D.C. National Research Council.

Parker, D., M. Lomax, C. Seal, and J. Wilton. 1995. Metabolic implications of ammonia production in the ruminant. Proc. Nutr. Soc. 54:549-563.

Ramirez Ramirez, H. A., K. Harvatine, and P. Kononoff. 2016. Forage particle size and fat intake affect rumen passage, the fatty acid profile of milk, and milk fat production in dairy cows consuming dried distillers grains with solubles. J. Dairy Sci. 99:392-398.

Reynolds, C., and N. B. Kristensen. 2008. Nitrogen recycling through the gut and the nitrogen economy of ruminants: An asynchronous symbiosis. J. Anim. Sci. 86(E. Suppl.):E293-E305.

Russell, J. B., J. O'connor, D. Fox, P. Van Soest, and C. Sniffen. 1992 A net carbohydrate and protein system for evaluating cattle diets: I. Ruminal fermentation. J. Anim. Sci. 70:3551-3561.

Rustomo, B., O. AlZahal, N. Odongo, T. Duffield, and B. McBride. 2006. Effects of rumen acid load from feed and forage particle size on ruminal $\mathrm{pH}$ and dry matter intake in the lactating dairy cow. J. Dairy Sci. 89:4758-4768.

Tamminga, S., A. Van Vuuren, C. Van der Koelen, R. Ketelaar, and P. van der Togt. 1990. Ruminal behaviour of structural carbohydrates, non-structural carbohydrates and crude protein from concentrate ingredients in dairy cows. Neth. J. Agric. Sci. 38(3B):513526.

Thoetkiattikul, H., W. Mhuantong, T. Laothanachareon, S. Tangphatsornruang, V. Pattarajinda, L. Eurwilaichitr, and V. Champreda. 2013. Comparative analysis of microbial profiles in cow rumen fed with different dietary fiber by tagged $16 \mathrm{~S}$ rRNA gene pyrosequencing. Curr. Microbiol. 67:130-137.

Turgeon, O., D. Brink, and R. Britton. 1983. Corn particle size mixtures, roughage level and starch utilization in finishing steers diets. J. Anim. Sci. 57:739-749.

Van Soest, P., J. Robertson, and B. Lewis. 1991. Symposium: Carbohydrate methodology, metabolism, and nutritional implications in dairy cattle. J. Dairy Sci. 74:3583-3597.

White, R., Y. Roman-Garcia, J. Firkins, M. VandeHaar, L. Armentano, W. Weiss, T. McGill, R. Garnett, and M. Hanigan. 2017. Evaluation of the National Research Council (2001) dairy model and derivation of new prediction equations. 1. Digestibility of fiber, fat, protein, and nonfiber carbohydrate. J. Dairy Sci. 100:3591-3610.

Wickersham, T., E. Titgemeyer, and R. Cochran. 2009. Methodology for concurrent determination of urea kinetics and the capture of recycled urea nitrogen by ruminal microbes in cattle. Animal 3:372-379.

Wickersham, T., E. Titgemeyer, R. Cochran, E. Wickersham, and D. Gnad. 2008a. Effect of rumen-degradable intake protein supplementation on urea kinetics and microbial use of recycled urea in steers consuming low-quality forage. J. Anim. Sci. 86:3079-3088.

Wickersham, T., E. Titgemeyer, R. Cochran, E. Wickersham, and E. Moore. 2008b. Effect of frequency and amount of rumen-degradable intake protein supplementation on urea kinetics and microbial use of recycled urea in steers consuming low-quality forage. J. Anim. Sci. 86:3089-3099.

Yang, W., K. Beauchemin, and L. Rode. 2001. Effects of grain processing, forage to concentrate ratio, and forage particle size on rumen $\mathrm{pH}$ and digestion by dairy cows. J. Dairy Sci. 84:2203-2216. 